\title{
Exergy analysis of a hybrid ground-source heat pump system
}

\author{
Kathrin Menberg ${ }^{* 1,2}$, Yeonsook Heo², Wonjun Choi ${ }^{3}$, Ryozo Ooka ${ }^{3}$, Ruchi Choudhary ${ }^{1}$, \\ Masanori Shukuya ${ }^{4}$ \\ 1 University of Cambridge, Department of Engineering, Trumpington Street, Cambridge, UK, \\ kcm30@cam.ac.uk, rc488@cam.ac.uk \\ 2 University of Cambridge, Department of Architecture, 1-5 Scroope Terrace, Cambridge, UK, \\ yh305@cam.ac.uk \\ 3 University of Tokyo, Institute of Industrial Science, 4-6-1 Komaba Meguro-ku, Tokyo, Japan, \\ wonjun@iis.u-tokyo.ac.jp, ooka@iis.u-tokyo.ac.jp \\ 4 Tokyo City University, Department of Restoration Ecology and Built Environment, Tokyo, Japan, \\ shukuya@tcu.ac.jp \\ * Corresponding author
}

\begin{abstract}
In contrast to energy analysis, the analysis of exergy allows the evaluation of the quality of different energy flows and enables a comprehensive assessment of inefficiencies within a system and its individual components by accounting for exergy consumption. While exergy analysis methods have been applied to a variety of conventional and renewable energy supply systems, there is still a lack of knowledge regarding the exergy flows and exergy efficiency of hybrid ground-source heat pump systems with a supplementary boiler. In this study, we develop a thermodynamic model for each subsystem in a hybrid heating and cooling system of an existing building by applying the concept of cool and warm exergy. A comparison of the exergy consumption of the hybrid system in heating and cooling reveals that there are significant differences regarding the components that attribute most to the overall exergy consumption in the system. Due to these differences the true exergy performance of the system in heating mode $(\sim 30 \%)$ is twice as high as for cooling mode $(\sim 15 \%)$, while the natural exergy performance is considerably better in cooling mode ( $26 \%$ to $\sim 3 \%)$. Potential measures to enhance the exergy performance based on changes in the operational settings of the system and the improvement of the building envelope were found to have a more significant effect on heating performance than on cooling performance. In general, measures that affect the amount of thermal energy delivered by the system appear to be more effective than changes to the operational settings of energy supply systems.
\end{abstract}

\section{Keywords}

Exergy Analysis; Ground Source Heat Pump Systems; Hybrid Systems; Energy Analysis.

\section{Nomenclature}

\section{Variables}

$\begin{array}{ll}C & \text { specific heat capacity }[\mathrm{kJ} / \mathrm{kg} \mathrm{K}] \\ E & \text { power consumption }[\mathrm{kW}] \\ H X_{\text {eff }} & \text { effectiveness of the heat exchanger [-] }\end{array}$




\section{Subscripts}

\begin{tabular}{|c|c|}
\hline 0 & reference (outdoor) condition \\
\hline$b$ & geothermal circulation fluid, borehole heat exchanger \\
\hline boiler & boiler \\
\hline$c$ & condenser of the heat pump \\
\hline ceil & consumption at the ceiling \\
\hline comp & compressor of the heat pump \\
\hline cond & consumption at the condenser \\
\hline$C P$ & main circulation loop \\
\hline $\operatorname{divHP}$ & diverted heat pump loop \\
\hline $\operatorname{divH} X$ & diverted heat exchanger loop \\
\hline$e$ & evaporator of the heat pump \\
\hline evap & consumption at the evaporator \\
\hline$g$ & ground \\
\hline gex & consumption at the borehole heat exchanger \\
\hline$H P$ & heat pump \\
\hline$H X$ & heat exchanger \\
\hline HXIoad & load side of the heat exchanger \\
\hline HXpump & boiler loop circulation pump \\
\hline HXsource & source side of the heat exchanger \\
\hline in & system/component inlet \\
\hline ind & indoor \\
\hline load & load side of component \\
\hline loss & consumption due to imperfect heat exchange \\
\hline $\operatorname{mix}$ & mixing valve after heat pump $(\mathrm{HP})$ or heat exchanger $(\mathrm{HX})$ \\
\hline$N G$ & natural gas \\
\hline out & component/system outlet \\
\hline power & electricity input \\
\hline pump & ground loop circulation pump \\
\hline re & return, i.e. system/component inlet \\
\hline refcycle & consumption in the refrigerant cycle \\
\hline source & source side of component \\
\hline
\end{tabular}

irreversibility factor [-]

mass flow rate $[\mathrm{kg} / \mathrm{s}]$

energy [kW]

ratio of chemical exergy for natural gas [-]

temperature $[\mathrm{K}]$

exergy [kW]

efficiency [-] 


$\begin{array}{ll}\begin{array}{ll}\text { sup } \\ \text { tot }\end{array} & \text { supply, i.e. system outlet } \\ \text { transfer } & \text { total efficiency/input } \\ \text { val } & \text { consumption during heat exchange } \\ w & \text { consumption in the mixing valves } \\ w b & \text { heating/cooling fluid } \\ & \text { boiler loop fluid }\end{array}$

\section{Introduction}

In thermodynamics, the exergy content of a system is defined as the maximum theoretical amount of work that can be extracted from this system in relation to a certain reference state, which usually refers to temperature conditions outside of the investigated system [1]. The analysis of exergy contents and flows offers a concept to assess the quality of energy, which has been applied in various fields of energy research, such as utilization and storage of energy [2-4], renewable and sustainable energy technologies [5-9] and energy processes [10-13]. The analysis of exergy (or $2^{\text {nd }}$ law analysis) quantifies the quality of different energy flows through a system and so enables a comprehensive assessment of all important aspects of energy utilisation [14]. In addition, exergy consumption, which represents a reduction in the ability of the system to deliver thermal energy, can be quantified on a detailed level for individual subsystems of energy supply systems and thus enable a more thorough examination of system efficiency than energy analysis [15]. Furthermore, by applying exergy analysis the magnitude and location of thermodynamic imperfections can be identified. Thus, exergy analysis methods are also ideal when system improvement is needed [16].

With a large amount of energy being used for space heating and cooling there has been an increasing interest in applying exergy analysis to understand the overall utility of energy supply systems with the aim of optimizing efficiency [17-20]. Several recent studies used exergy analysis for the evaluation of operation and control strategies of conventional HVAC systems [21-24], while other studies compared the overall energy and exergy performance of such systems under different climatic conditions and for different reference states [25-29]. With the increasing use of renewable energy technologies for space heating, recent years have seen a large amount of work on the exergetic evaluation of ground, solar and air-sourced heat pump systems [30-34]. These studies have shown that systems using renewable energy sources are typically favourable with regard to exergy performance, when combined with a moderate temperature heating systems, such as radiant floor or wall-mounted systems [35]. This is due to the low temperature spread between heat source and supply system, which results in lower entropy generation and consequently in lower exergy consumption [36, 37]. Evaluation of water-based systems for space cooling that employ renewable energy source, on the other hand, can be found less frequently in literature [38,39], and studies investigating systems for both space heating and cooling from one system are still rare $[40,41]$.

Also, recent developments and increasing popularity of hybrid GSHP systems with additional heat sources or sinks are not yet reflected in available methods for exergy analysis of such systems [42, 43]. So far, only two studies investigated the exergy flows and efficiencies for a GSHP system with additional 
heat sinks, such as a cooling tower or a crawl-space below a residential building [29, 39, 44]. However, to our knowledge no study has investigated the exergetic performance of a GSHP system with a supplementary, gas-fired boiler, although this type of system is becoming increasingly popular due to lower installation and operational costs [45]. The introduction of a boiler component to the low or moderate temperature system will be interesting, as such a high-temperature component has the potential to significantly affect the exergy efficiency and consumption in the system. Consequently, the performance of such a hybrid system might also differ significantly in heating and cooling mode.

Such a detailed investigation requires a detailed analysis on the level of individual system components, which was so far conducted only by Li et al. [38] for a GSHP and ASHP system in cooling mode. In addition, comparing the performance of the system in heating and cooling mode in detail also requires taking into account the different types of exergy, warm and cool, and thus a more complex analysis than the standard approach follow by the vast majority of existing studies. Indeed, a recent review on GSHP systems highlighted the benefits of detailed, analytical exergy analysis to identify irreversibilities at different locations in the system, and concluded that further improvements of this method offer a large potential to enhance the efficiency of GHSP systems [46].

To address the research gaps highlighted above, we carry out a detailed exergy analysis of a hybrid system with a supplementary boiler operating in both heating and cooling modes. To do so, we develop a comprehensive and novel thermodynamic model comprising of all technical components under consideration of warm and cool exergy. The thermodynamic model constitutes new formulations for the energy and exergy terms for the subsystems relating to the supplementary boiler, such as the heat exchanger and the mixing valves. We assess exergy efficiency at different levels and according to the different energy and exergy sources, such as natural and non-natural exergy, to allow a detailed comparison of different aspects of system performance in different operational modes. To demonstrate the application of exergy analysis to real systems in the context of system design and management, we investigate three different hypothetical scenarios for potential improvement of the performance of the hybrid system relating to changes in equipment, operational strategies and building envelope improvements. In addition this scenario analysis will reveal new insights into the dependency of exergy values and performance of individual system components on operational conditions, as previous studies conducted either parametric studies regarding the reference temperature [29, 41], or analysis on a (sub)system level $[40,47]$. The impact of these system and building variations is discussed with regard to changes in exergy balance, performance indicators and exergy consumption in individual system components.

\section{Exergy theory}

According to Shukuya [48] exergy is defined as a measure for the dispersion potential of energy, while entropy is a measure for this dispersion of energy. Furthermore, exergy can be considered as warm or cool exergy depending on the system temperature $T$ and the reference temperature $T_{0}$. If the system temperature is higher than reference $T_{0}$, the thermal energy $Q$ contained in the system can disperse into the environment, which acts as a cold reservoir, as a flow of warm exergy (eq. 1). If the environment 
is warmer than the system, it contains more thermal energy $Q$ than the system at $T$, so that exergy in form of cool exergy can flow into the system (eq. 2) [1].

$$
\begin{aligned}
& X_{\text {warm }}=\left(1-\frac{T_{0}}{T}\right) Q, \text { for } T>T_{0} \\
& X_{\text {cool }}=\left(1-\frac{T_{0}}{T}\right)\left(-Q^{*}\right), \text { for } T_{0}>T
\end{aligned}
$$

In accordance with the principle of energy conservation and entropy generation, it is possible to obtain the general energy and entropy balance equations for any system under consideration given in eq. 3 and 4 [38]:

$$
\begin{aligned}
& {[\text { energy input }]=[\text { energy stored }]+[\text { energy output }]} \\
& {[\text { entropy input }]+[\text { entropy generated }]=[\text { entropy stored }]+[\text { entropy output }]}
\end{aligned}
$$

As exergy $=$ energy - entropy $\cdot T_{0}$, a general exergy balance equation for any system can be written as eq. 5 [38], where the exergy storage term can be disregarded for steady state system evaluations.

$$
[\text { exergy input }]-[\text { exergy consumed }]=[\text { exergy stored }]+[\text { exergy output }]
$$

\section{Modelling approach}

\subsection{System overview}

The Architecture studio building of the University of Cambridge is used as a case study for an existing building with a hybrid GSHP system. The upper floor of the two-storey building contains an open office space of approx. $325 \mathrm{~m}^{2}$, which is used as a design studio. Heating and cooling for this space is provided by the hybrid GSHP system, which consists of two vertical borehole heat exchangers (BHE) each 45m deep and a reversible brine-to-water heat pump (HP). Thermal energy is supplied to the room through radiant ceiling panels covering about half of the ceiling area. Due to the local climatic conditions dehumidification is not required, and accordingly not provided by the system. In the winter season, the GSHP is used to preheat the building return flow, while supplementary heat is provided by a heat exchanger $(\mathrm{HX})$ connected to a gas-fired boiler. In summer, the total cooling demand of the space is provided by the GSHP system.

Figure 1 presents a schematic overview of the water-based hybrid GHSP system and the relevant system components for cooling and heating mode. The main return flow from the ceiling panels in the building is split before the heat pump, so that only a fraction of the main circulation flow passes through the evaporator (in cooling mode) or the condenser (in heating mode) of the heat pump. The other fraction of the flow is diverted, and both flows are then brought together in the heat pump mixing valve. In cooling mode, this flow represents the supply flow to the ceiling panels, while in heating mode two additional components must be considered. The mixed flow from the heat pump is then separated again into a fraction that flows through the heat exchanger, and a second fraction which bypasses the heat exchanger. Both fractions of the main circulation flow are merged in a second mixing valve after the heat exchanger, and form the heating supply flow. 


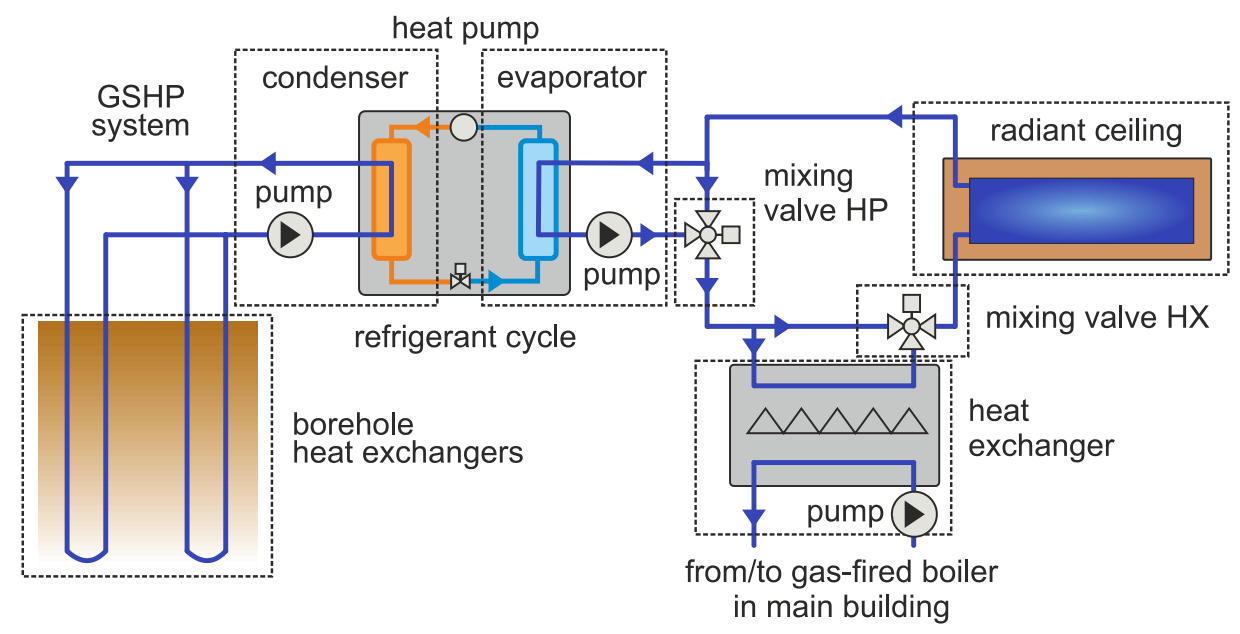

Figure 1: Schematic overview of the energy supply system of the case study and the individual components of the hybrid heating and cooling system.

For the analytical exergy modelling under steady-state conditions we apply the design temperature values of the system as listed in Table 1 . The selected outdoor temperatures $T_{0}$ represent typical reference temperature values for exergy analysis of heating and cooling systems in moderate climates $[26,39]$ and the indoor temperature $T_{\text {in }}$ is adopted from the set point temperature of the studio space. According to the building management, the heating and cooling set point temperature for the Studio room is $21^{\circ} \mathrm{C}$. The average surface temperature of the radiant ceiling panels is unknown, so we model the ceiling in combination with the indoor space, and use the indoor air temperature as internal temperature of this component. The rather low cooling set point temperature is due to internal heat gains from dense occupancy at peak times, physical activity of the occupants, and waste heat from the workshop on the ground floor. In addition, the radiative environment formed by the surface temperatures of other construction surfaces, such as windows, must be particularly considered for the performance of a radiant ceiling.

Table 1: Temperatures and mass flow rates used for exergy analysis of the system in cooling and heating mode, and electricity consumed by pumps and the compressor of heat pump. The heat exchanger, boiler and mixing valve $\mathrm{HX}$ are only used in heating mode. All values represent the design values based on the system specifications.

\begin{tabular}{lcccc}
\hline Temperature & \multicolumn{2}{c}{ cooling design values } & \multicolumn{2}{c}{ heating design values } \\
\hline$T_{0}$ & $30^{\circ} \mathrm{C}$ & $303 \mathrm{~K}$ & $0^{\circ} \mathrm{C}$ & $273 \mathrm{~K}$ \\
$T_{\text {ind }}$ & $21^{\circ} \mathrm{C}$ & $294 \mathrm{~K}$ & $21^{\circ} \mathrm{C}$ & $294 \mathrm{~K}$ \\
$T_{g}$ & $13^{\circ} \mathrm{C}$ & $286 \mathrm{~K}$ & $13^{\circ} \mathrm{C}$ & $286 \mathrm{~K}$ \\
$T_{b, \text { int }}$ & $23.1^{\circ} \mathrm{C}$ & $296.1 \mathrm{~K}$ & $6^{\circ} \mathrm{C}$ & $279 \mathrm{~K}$ \\
$T_{b, \text { out }}$ & $18^{\circ} \mathrm{C}$ & $291 \mathrm{~K}$ & $9{ }^{\circ} \mathrm{C}$ & $282 \mathrm{~K}$ \\
$T_{c}$ & $27^{\circ} \mathrm{C}$ & $300 \mathrm{~K}$ & $42^{\circ} \mathrm{C}$ & $315 \mathrm{~K}$ \\
$T_{e}$ & $12^{\circ} \mathrm{C}$ & $285 \mathrm{~K}$ & $4^{\circ} \mathrm{C}$ & $277 \mathrm{~K}$ \\
$T_{H X, \text { source, } i n}$ & - & - & $82^{\circ} \mathrm{C}$ & $355 \mathrm{~K}$ \\
$T_{H X, \text { source,out }}$ & - & - & $71^{\circ} \mathrm{C}$ & $344 \mathrm{~K}$ \\
$T_{r e}$ & $20^{\circ} \mathrm{C}$ & $293 \mathrm{~K}$ & $36^{\circ} \mathrm{C}$ & $309 \mathrm{~K}$
\end{tabular}




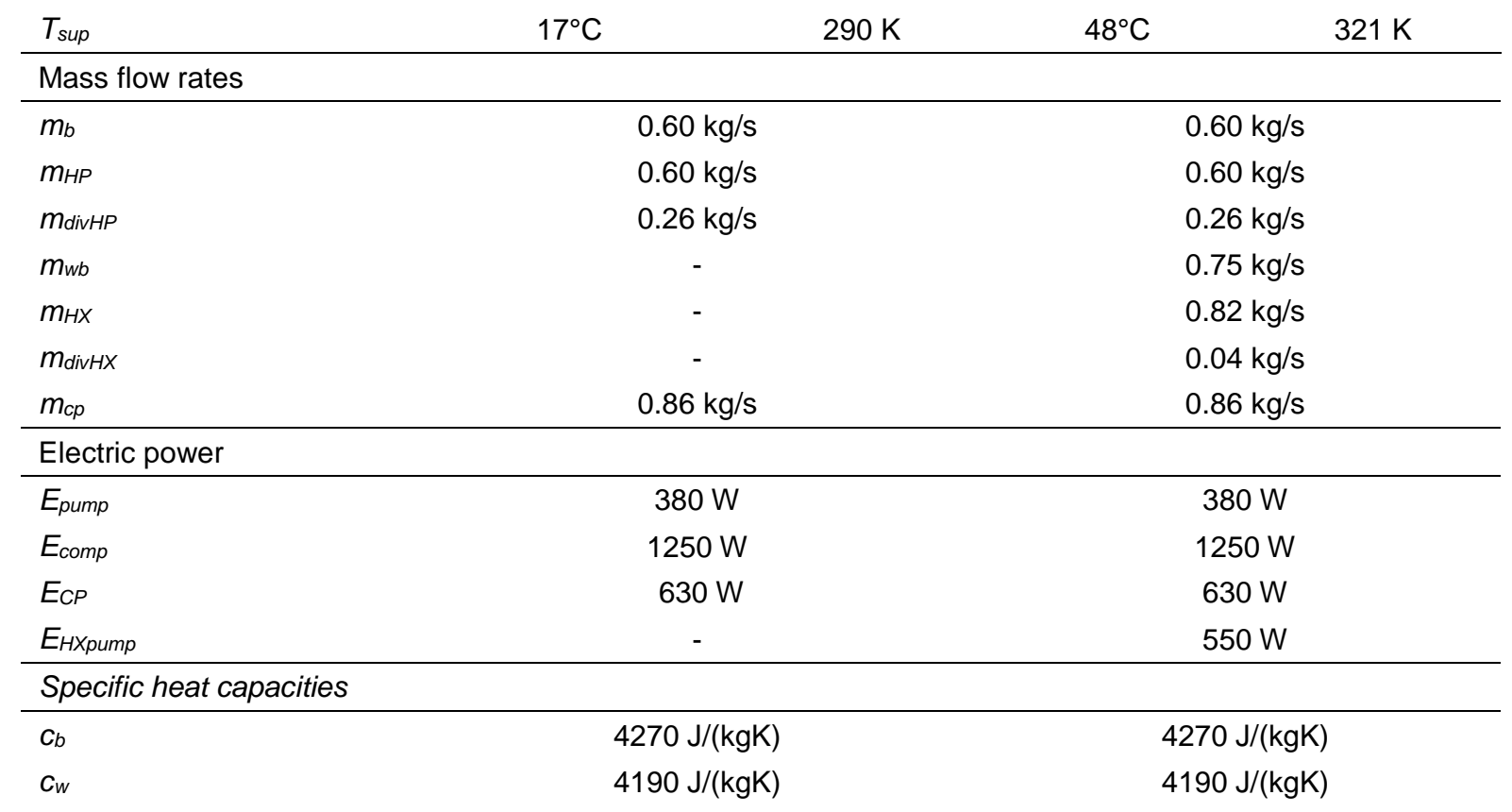

The definition of the ground temperature, $T_{g}$, is based on the assumption of a long-term thermal equilibrium between the atmosphere, with an average annual air temperature of approx. $10^{\circ} \mathrm{C}$, and the ground with slightly increased subsurface temperatures of $3 \mathrm{~K}$ due to the urban setting of the investigated building [49]. The inlet and outlet temperatures of the heat carrier fluid in the BHE, $T_{b, \text { in }}$ and $T_{b, \text { out, }}$ are set to match the design capacity of the BHE of $7 \mathrm{~kW}$ and $14 \mathrm{~kW}$ for heating and cooling respectively. The values of the condensing and evaporation temperatures $T_{c}$ and $T_{e}$ of the heat pump are defined based on the source and load side inlet and outlet flow temperatures of the respective season and are within the range of typically assumed values for $T_{c}$ and $T_{e}$ in literature $[38,41,44,50]$.

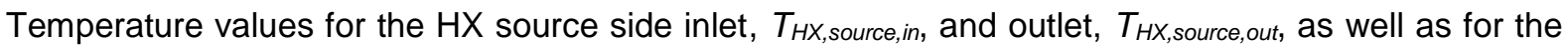
energy supply $T_{\text {sup }}$ and return flow $T_{r e}$ were obtained from the mechanical installation drawings, which were also used to obtain the mass flow rates of the specific system parts. The characteristics of the electric and mechanical components of the system, such as the power demand of the pumps, were taken from constructions plans and technical information sheets. For the exergy modelling we assume steady state conditions and focus mainly on thermal exergy, which leads to the exergy equations listed in the following parts of this section.

\subsection{Heating mode}

In order to analyse the steady-state exergy flow through the energy supply system and the exergy consumption by the individual components it is necessary to divide the system into its basic components [38]. For the hybrid system operating in heating mode, these are: the borehole heat exchanger, the evaporator of the heat pump, the refrigerant in the heat pump, the condenser, the mixing valve after the heat pump, the heat exchanger, the mixing valve after the heat exchanger and the radiant ceiling. An overview of the components used by the supply system operating in heating mode and the corresponding terms for energy, exergy and temperatures applying to the individual components is given Figure 2. 
$\begin{array}{ll}\text { a) } \mathrm{BHE} & \text { b) evaporator }\end{array}$

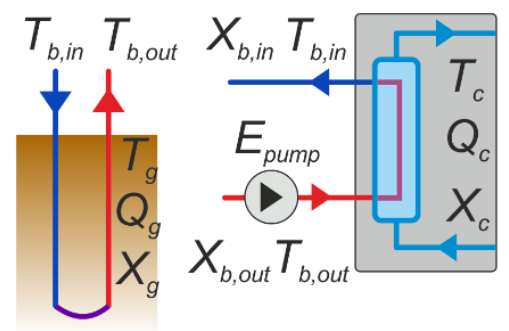

c) refrigerant

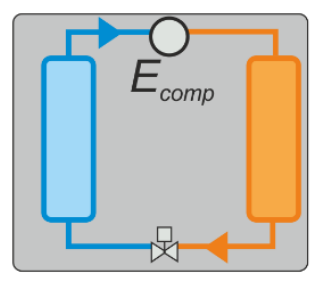

f) heat exchanger

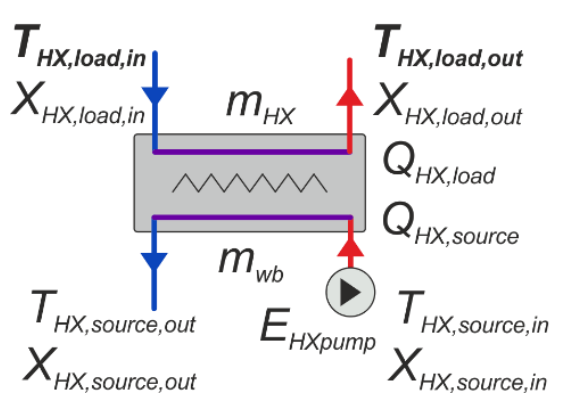

d) condenser

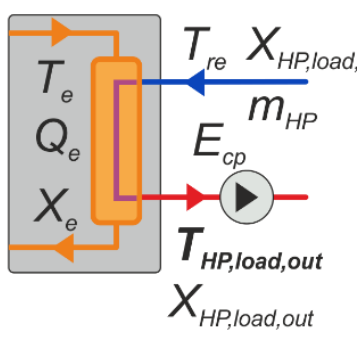

e) mixing valve $\mathrm{HP}$

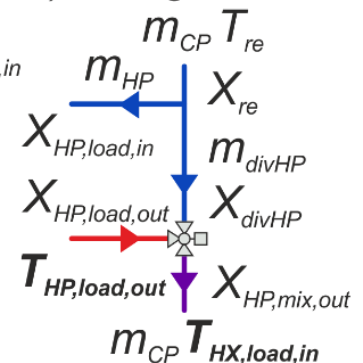

Figure 2: Subsystems used for heating as represented by the exergy model for heating mode with the energy, exergy and temperature terms applying to the corresponding components. Temperatures in bold are inferred from the model by balancing the energy input and output of the corresponding component.

Detailed equations for calculating exergy contents and flows based on the concept of warm and cool exergy for a borehole heat exchanger and the different components of a heat pump were derived by $\mathrm{Li}$ et al. [38] for a system in cooling mode. To make the equations applicable to heating mode, changes in flow direction of energy and exergy, and the reverse operational mode of the heat pump have to be taken into account. The corresponding equations can be found in Appendix B. As we focus on modelling the exergy flows in the system analytically and under steady-state conditions, we choose to quantify the energy exchanged with the ground based on the provided system temperatures, and thus disregard physical details of heat transfer in the subsurface and inside the ground heat exchanger. For components e) - h) in Figure 2 we derived new formulations following the same concept as applied by Li et al. [38] to maintain consistency in the approach.

\subsubsection{Mixing valve after the heat pump}

In the mixing valve after the heat pump the flow through the heat pump, $m_{H P}$, is combined with the flow that bypassed the heat pump, $m_{\text {divHP. }}$. The energy balance for the mixing valve is defined by the corresponding contents of thermal energy of the two inlet flows and the outlet flow (eq. 6). The exergy balance (eq. 7 ) is formed of the corresponding exergy contents of the inlet $X_{H P \text {,load,out }}$ (eq. A.22) and $X_{\text {divHP }}$ (eq. 8), outlet flow $X_{H P \text {,mix, out }}$ (eq. 9), which represents the inlet flow to heat exchanger component

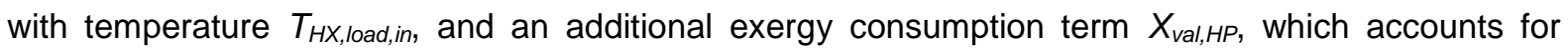
entropy generated during the mixing process. The derivation of the general form of eqs. (8) and (9) is shown in Appendix A. 


$$
\begin{aligned}
& c_{w} m_{H P}\left(T_{H P, \text { load,out }}-T_{0}\right)+c_{w} m_{\text {div } H P}\left(T_{r e}-T_{0}\right)=c_{w} m_{C P}\left(T_{H X, \text { load }, \text { in }}-T_{0}\right) \\
& X_{\text {divHP }}+X_{H P, \text { load,out }}-X_{\text {val }, H P}=X_{H P, \text { mix }, \text { out }} \\
& X_{\text {divHP }}=c_{w} m_{\text {divH } P}\left\{\left(T_{r e}-T_{0}\right)-T_{0} \ln \frac{T_{r e}}{T_{0}}\right\} \\
& X_{H P, \text { mix }, \text { out }}=c_{w} m_{C P}\left\{\left(T_{H X, \text { load,in }}-T_{0}\right)-T_{0} \ln \frac{T_{H X, \text { load,in }}}{T_{0}}\right\}
\end{aligned}
$$

\subsubsection{Heat exchanger}

For the overall energy balance of the heat exchanger $(\mathrm{HX})$ in eq. 10 , which is based on the general energy balance in eq. 3, we assume a non-ideal heat exchanger with a separate term for energy loss. This heat loss is defined by the heat exchanger effectiveness $H X_{\text {eff, }}$ which is assumed to be 0.95 [51]. $Q_{H X, \text { source, in }}$ and $Q_{H X, \text { load,in }}$ represent the energy contents of the source and load side inlet flows, respectively, and $Q_{H X, \text { source,out }}$ and $Q_{H X, \text { load,out }}$ represent the energy contents of the corresponding outlet flows. $Q_{H X \text {,source,in }}$ and $Q_{H X, \text { source,out }}$ can be quantified by the corresponding temperatures and mass flow rates using the relation $Q=C_{W}{ }^{*} m^{*}\left(T-T_{0}\right)$ (Figure 2) and the values from Table 1, while for $Q_{H X, \text { load, in }}$ $T_{H X, \text { load, in }}$ can be inferred by rearranging eq. 6 . The internal energy balance of the $H X$ is given in eq. 11 , where $Q_{H X, \text { source }}$ is the energy input through the source side and $Q_{H X, \text { load }}$ the energy output on the load side, which differs from the source side input by the energy loss $H X_{\text {eff. }}$ The corresponding exergy

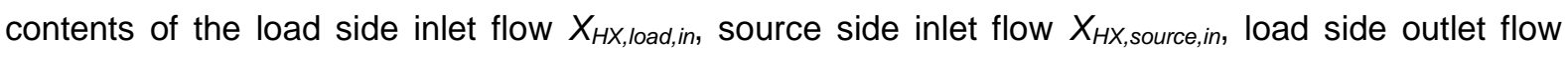

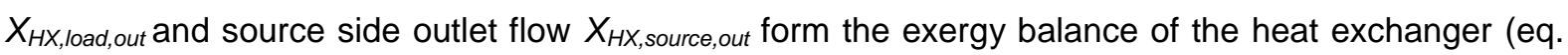
12). It also takes into account the power consumption of the pump used in boiler circulation loop, $E_{H X \text {,pump }}$, and the exergy consumption $X_{H X}$. (eq. 13), which arises from two sources: exergy consumption $X_{H X, \text { loss }}$ due to imperfect heat exchange related to $H X_{\text {eff }}$ (eq. 14), and exergy consumption during heat exchange $X_{H X, \text { transfer. }}$

$$
\begin{aligned}
& Q_{H X, \text { source, in }}+Q_{H X, \text { load,in }}-\left(1-H X_{e f f}\right) \times Q_{H X, \text { source }}=Q_{H X, \text { source,out }}+Q_{H X, \text { load }, \text { out }} \\
& Q_{H X, \text { source }}-\left(1-H X_{e f f}\right) \times Q_{H X, \text { source }}=Q_{H X, \text { load }} \\
& E_{H X P \text { pum }}+X_{H X, \text { source, in }}+X_{H X, \text { load,in }}-X_{H X}=X_{H X, \text { load,out }}+X_{H X, \text { source,out }} \\
& X_{H X}=X_{H X, \text { transfer }}+X_{H X, \text { loss }} \\
& X_{H X, \text { loss }}=\left(1-\frac{T_{0}}{0.5 *\left(T_{H X, \text { source, } \text { in }}+T_{H X, \text { source }, \text { out })}\right)}\right) \times\left(1-H X_{\text {eff }}\right) \times Q_{H X, \text { source }}
\end{aligned}
$$

Energy and exergy balance equations for the source side of the heat exchanger, which is connected to the boiler, are given by eqs. $15-18$, where $X_{H X \text {,source }}$ is the amount of exergy exchanged between the source side fluid and the heat exchanger.

$$
\begin{aligned}
& E_{H X P U m p}+c_{w} m_{w b}\left(T_{H X, \text { source, in }}-T_{0}\right)=Q_{H X, \text { source }}+c_{w} m_{w b}\left(T_{H X, \text { source,out }}-T_{0}\right) \\
& X_{H X, \text { source }, \text { in }}=c_{w} m_{w b}\left\{\left(T_{H X, \text { source, in }}-T_{0}\right)-T_{0} \ln \frac{T_{H X, \text { source, } i n}}{T_{0}}\right\} \\
& X_{H X, \text { source,out }}=c_{w} m_{w b}\left\{\left(T_{H X, \text { source,out }}-T_{0}\right)-T_{0} \ln \frac{T_{H X, \text { source }, \text { out }}}{T_{0}}\right\} \\
& X_{H X, \text { Source }}=X_{H X, \text { source, in }}-X_{H X, \text { source,out }}
\end{aligned}
$$


Looking at the load side of the heat exchanger there are two different ways to calculate the energy transferred from the heat exchanger to the load side fluid $Q_{H X, \text { load: }}$ based on the source side energy $Q_{H X, \text { source }}$ and the effectiveness $H X_{\text {eff }}$ (eq. 19), which is assumed to be 0.95 [51], or based on the load side energy balance (eq. 20). As the design temperatures for $T_{H X, \text { load,in }}$ and $T_{H X, \text { load,out }}$ are not specified in the technical description of the case study system, eq. 19 is used here. The exergy contents of the load inlet flow $X_{H X, \text { load, in }}$ and outlet flow $X_{H X, \text { load, out }}$ are given by eqs. 21 and 22.

$$
\begin{aligned}
& Q_{H X, \text { source }} \times H X_{e f f}=Q_{H X, \text { load }} \\
& Q_{H X, \text { load }}+c_{w} m_{H X}\left(T_{H X, \text { load,in }}-T_{0}\right)=c_{w} m_{H X}\left(T_{H X, \text { load }, \text { out }}-T_{0}\right) \\
& X_{H X, \text { load,in }}=c_{w} m_{w}\left\{\left(T_{H X, \text { load }, \text { in }}-T_{0}\right)-T_{0} \ln \frac{T_{H X, \text { load }, \text { in }}}{T_{0}}\right\} \\
& X_{H X, \text { load,out }}=c_{w} m_{w}\left\{\left(T_{H X, \text { load }, \text { out }}-T_{0}\right)-T_{0} \ln \frac{T_{H X, \text { load }, \text { out }}}{T_{0}}\right\}
\end{aligned}
$$

\subsubsection{Mixing valve after the heat exchanger}

In the second mixing valve after the heat exchanger the flow from the HX $m_{H X}$ is merged with the bypassed flow $m_{\text {divHX }}$ to the heating supply flow $m_{C P}$. The according energy and exergy balances are given by eq. 23 and 24, where $X_{\text {divHX }}$ represents the exergy content of the bypassed flow (eq. 25), $X_{\text {Val, HX }}$ is the exergy consumption in the $\mathrm{HX}$ mixing valve, and $X_{\text {sup }}$ is the exergy content of the supply flow (eq. 26).

$$
\begin{aligned}
& c_{w} m_{H X}\left(T_{H X, \text { load,out }}-T_{0}\right)+c_{w} m_{\text {div } X}\left(T_{H X, \text { load }, \text { in }}-T_{0}\right)=c_{w} m_{C P}\left(T_{\text {sup }}-T_{0}\right) \\
& X_{\text {divHX }}+X_{H X, \text { load }, \text { out }}-X_{\text {val }, H X}=X_{\text {sup }} \\
& X_{\text {divHX }}=c_{w} m_{\text {div } H}\left\{\left(T_{H X, \text { load, }, \text { in }}-T_{0}\right)-T_{0} \ln \frac{T_{H X, \text { load }, \text { in }}}{T_{0}}\right\} \\
& X_{\text {sup }}=c_{w} m_{C P}\left\{\left(T_{\text {sup }}-T_{0}\right)-T_{0} \ln \frac{T_{\text {sup }}}{T_{0}}\right\}
\end{aligned}
$$

\subsubsection{Radiant ceiling}

The energy balance for the radiant ceiling subsystem is given by eq. 27 and the corresponding exergy balance by eq. 28. Exergy input is provided by the exergy content of the supply flow $X_{\text {sup }}$, while the output term is formed of the exergy content of the return flow $X_{r e}$ (eq. 30) and the exergy delivered to the room $X_{\text {out }}$ (eq. 29). Exergy consumption during heat exchange in the ceiling is denoted by $X_{\text {ceil. }}$. The exergy output to the room, $X_{\text {out }}$, is assigned a positive sign, because of the direction of the exergy flow. This temperature relation indicates that warm exergy flows from the heating loop circulation fluid into the room. The overall energy balance of the cooling loop is given by eq. 31 .

$$
\begin{aligned}
& c_{w} m_{C P}\left(T_{\text {sup }}-T_{\text {ind }}\right)=c_{w} m_{C P}\left(T_{\text {re }}-T_{\text {ind }}\right)+Q_{\text {out }} \\
& X_{\text {sup }}-X_{\text {ceil }}=X_{\text {re }}+X_{\text {out }} \\
& X_{\text {out }}=\left(1-\frac{T_{0}}{T_{\text {ind }}}\right) Q_{\text {out }} \\
& X_{r e}=c_{w} m_{C P}\left\{\left(T_{r e}-T_{0}\right)-T_{0} \ln \frac{T_{r e}}{T_{0}}\right\} \\
& Q_{c}+E_{C P}+Q_{H X, \text { load }}=Q_{\text {out }}
\end{aligned}
$$




\subsection{Cooling mode}

In cooling mode, the heat pump operates in reverse to heating mode so that the refrigerant in the evaporator receives heat from the cooling circulation fluid and releases it to the fluid in the BHE in the condenser (Figure 3). Accordingly, the ground is used to cool the heat carrier fluid in the BHE, which enters the condenser side of the heat pump, where the compressed, but still vapour-state refrigerant fluid condenses and releases heat into the BHE circulation fluid. In the expansion valve a distinct pressure drop leads to the evaporation of the liquid refrigerant, which then enters the evaporator side of the heat pump at a low temperature and evaporates by receiving heat from the load side fluid. Thus, the load side fluid cools down and then has the ability to cool the radiant ceiling panels and the adjacent indoor space. The equations defining the energy and exergy balances and contents of the individual subsystems are set up in the same manner as for cooling mode using the general equation for cool exergy (eq. 2), and are described in detail in Appendix C.

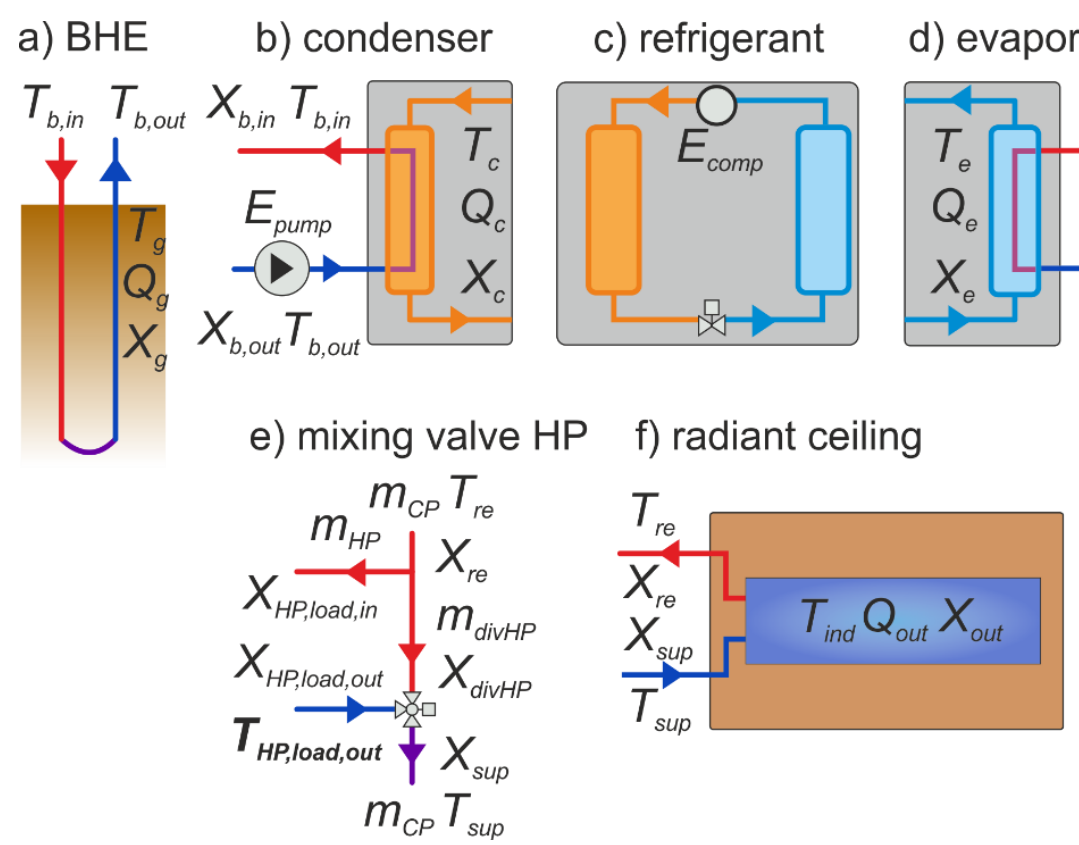

Figure 3: Subsystems used for cooling as represented by the exergy model for cooling mode with the energy, exergy and temperature terms applying to the corresponding components. Temperatures and mass flow rates in bold are inferred from the model by balancing the energy input and output of the respective component.

\subsection{Exergy from power grid and boiler}

For the calculation of the exergy input from the electricity grid to be consumed in the auxiliary components, we assume that the electricity is generated in a remote natural gas power station. The exergy for the individual components (heat pump, circulation pump, ground loop pump and HX pump) are given by the ratio of power demand and the overall efficiency $\eta_{T O T}$, which includes the conversion efficiency of the power plant and transmission efficiency of the grid, multiplied by the ratio of chemical exergy to higher heating value of natural gas, $r$ [39] (eqs. 32-36). 


$$
\begin{aligned}
& X_{\text {power }, H P}=\frac{E_{\text {comp }}}{\eta_{T O T}} r \\
& X_{\text {power }, C P}=\frac{E_{C P}}{\eta_{T O T}} r \\
& X_{\text {power, }, \text { ump }}=\frac{E_{\text {pump }}}{\eta_{T O T}} r \\
& X_{\text {power,HXpump }}=\frac{E_{H X \text { Xump }}}{\eta_{T O T}} r \\
& X_{\text {power,tot }}=X_{\text {power }, H P}+X_{\text {power }, C P}+X_{\text {power,pump }}+X_{\text {power }, \text { XXpump }}
\end{aligned}
$$

We assume $\eta_{\text {TOT }}$ to be 0.40 based on UK energy statistics [52], and $r$ as 0.93 , which is based on the assumption of natural gas as pure methane [1]. The calculation of the exergy input to the heat exchanger from the boiler $X_{N G, b o i l e r}$ due to combustion of natural gas is performed according to eq. 53) [34], where $\eta_{\text {boiler }}$ is the efficiency of the boiler, which we assume to be 0.9 [26]. Taking into account the ratio of chemical exergy to higher heating value of natural gas, $r$, links the primary energy input to the boiler to the exergy input (eq. 37).

$$
X_{N G, \text { boiler }}=\frac{Q_{H X, \text { source }}}{\eta_{\text {boiler }}} r
$$

\subsection{Performance indicators}

The actual coefficient of performance (COP) of the refrigerant cycle of the heat pump is smaller than the theoretical COP due to irreversibility effects during heat exchange. To calculate the actual COP of the refrigerant cycle we follow the approach of $\mathrm{Li}$ et al. [38], by taking into account the temperature differences of the heat pump system components for heating and cooling mode:

$$
\begin{aligned}
& \text { COP }_{\text {heating }}=k \frac{T_{c}}{T_{e}-T_{c}}=k \frac{T_{\text {in }}-\left(T_{\text {in }}-T_{c}\right)}{\left(T_{g}-T_{\text {in }}\right)+\left(T_{e}-T_{w}\right)+\left(T_{w}-T_{g}\right)+\left(T_{\text {in }}-T_{c}\right)} \\
& \text { COP }_{\text {cooling }}=k \frac{T_{e}}{T_{c}-T_{e}}=k \frac{T_{\text {in }}-\left(T_{\text {in }}-T_{e}\right)}{\left(T_{g}-T_{\text {in }}\right)+\left(T_{c}-T_{w}\right)+\left(T_{w}-T_{g}\right)+\left(T_{\text {in }}-T_{e}\right)}
\end{aligned}
$$

In equations (38) and (39), $k$ represents irreversibility factor of the refrigerant cycle, which is a function of the isentropic, mechanical and motor efficiency of the heat pump and typically ranges between 0.2 and $0.6[38,53,54]$. Therefore, we set it to 0.4 for both heating and cooling mode, as the ratio of actual and theoretical COP was shown to be similar for both modes [53]. The exergy performance of the heating and cooling system is analysed through six different exergy ratios (eqs. 40-45). We adopt the exergy efficiency of the system $\eta_{s}$, which is specified by the ratio of exergy output to all non-natural exergy inputs, and the natural exergy ratio of the system $\eta_{s 2}$, which represents the share of natural exergy input on the total exergy input from all sources, from [38] and define, in addition, a measure for the total efficiency of the system $\eta_{s 3}$, which relates the exergy output to the total exergy input:

$$
\eta_{s 1}=\frac{\text { exergy output }}{\text { non }- \text { natural exergy input }}=\frac{X_{\text {out }}}{E_{\text {comp }}+E_{C P}+E_{\text {pump }}+E_{H X, \text { pump }}+X_{H X s o u r c e}}
$$




$$
\begin{aligned}
& \eta_{s 2}=\frac{\text { natural exergy input }}{\text { total exergy input }}=\frac{X_{g}}{E_{\text {comp }}+E_{C P}+E_{\text {pump }}+E_{H X, p u m p}+X_{H X \text { source }}+X_{g}} \\
& \eta_{s 3}=\frac{\text { exergy output }}{\text { total exergy input }}=\frac{X_{\text {out }}}{E_{\text {comp }}+E_{C P}+E_{\text {pump }}+E_{H X, p u m p}+X_{H X \text { source }}+X_{g}}
\end{aligned}
$$

To quantify the overall exergy efficiency including the power grid and the gas-fired boiler we apply eqs. 43-45 based on the work by Kazanci et al. [39], where $\eta_{1}$ is the overall exergy efficiency, $\eta_{2}$ represents the natural overall exergy efficiency and $\eta_{3}$ the true overall exergy efficiency, respectively. The meaning of the efficiencies $\eta_{1}, \eta_{2}$, and $\eta_{3}$ corresponds to $\eta_{s 1}, \eta_{s 2}$, and $\eta_{s 3}$, respectively, with the difference that they relate the exergy output or natural input to the corresponding exergy inputs from the grid and take into account the efficiency of electricity generation and transmission.

$$
\begin{aligned}
\eta_{1} & =\frac{\text { exergy output }}{\text { electricty input }}=\frac{X_{\text {out }}}{X_{\text {power, } \text { tot }}} \\
\eta_{2} & =\frac{\text { natural exergy input }}{\text { total exergy input }}=\frac{X_{g}}{X_{\text {power, tot }}+X_{g}} \\
\eta_{3} & =\frac{\text { exergy output }}{\text { total exergy input }}=\frac{X_{\text {out }}}{X_{\text {power }, \text { tot }}+X_{g}}
\end{aligned}
$$

\section{Results and Discussion}

\subsection{Exergy values for the system components in heating mode}

Figure 4 shows the results for the exergy flow and consumption values of each component of the system in heating mode using the design values listed in Table 1. To verify the calculated energy and exergy values, we examine the energy and exergy balance equations given in the methodology, and find that they are fulfilled to a high degree of accuracy of $\pm 2.0^{*} 10^{-13} \mathrm{~W}$. In heating mode, the hybrid GSHP system works with three energy sources: the ground, the power from grid, and a gas-fired boiler. Therefore, exergy flow are plotted for each source separately. The plots show the sequential flow of exergy from each source, through the individual system components (marked on the x-axes), to the outdoor environment. The relative exergy content at the outdoor environment is zero because we use the outdoor temperature as the reference condition for the exergy analysis. The bar on the left side of each plot shows the magnitude of energy input from the source and the contribution of the individual components. The slope of each line segment indicates the rate at which exergy is consumed in the corresponding subsystem, while the dots between the individual components mark the amount of exergy flow from one subsystem to the next. Because we focus on analysing the heating and cooling system only, exergy flow is not explicitly quantified through the room and the building envelope.

Figure 4 a shows the flow of warm exergy from the ground, including the additional thermal exergy input from the heat pump and the boiler. It reveals that a considerable amount of exergy is consumed in the ceiling when the warm exergy is delivered to the room. This significant consumption in the radiative supply component is in contrast to findings from previous studies that investigated radiant floor systems, which exhibit a much lower exergy consumption [33, 35, 39], due to lower temperature spreads between the supply flow and the indoor temperature (see Table 1). The large exergy consumption in the heat exchanger $\left(X_{H X}=3.51 \mathrm{~kW}\right)$ is also due to the temperature difference between the source side (boiler) 
and the load side (heating loop). Indeed, components with a lower temperature difference between inputs and outputs, such as the mixing valves, show a very low exergy consumption and do not contribute significantly to the overall exergy consumption.

a) exergy flow from the ground
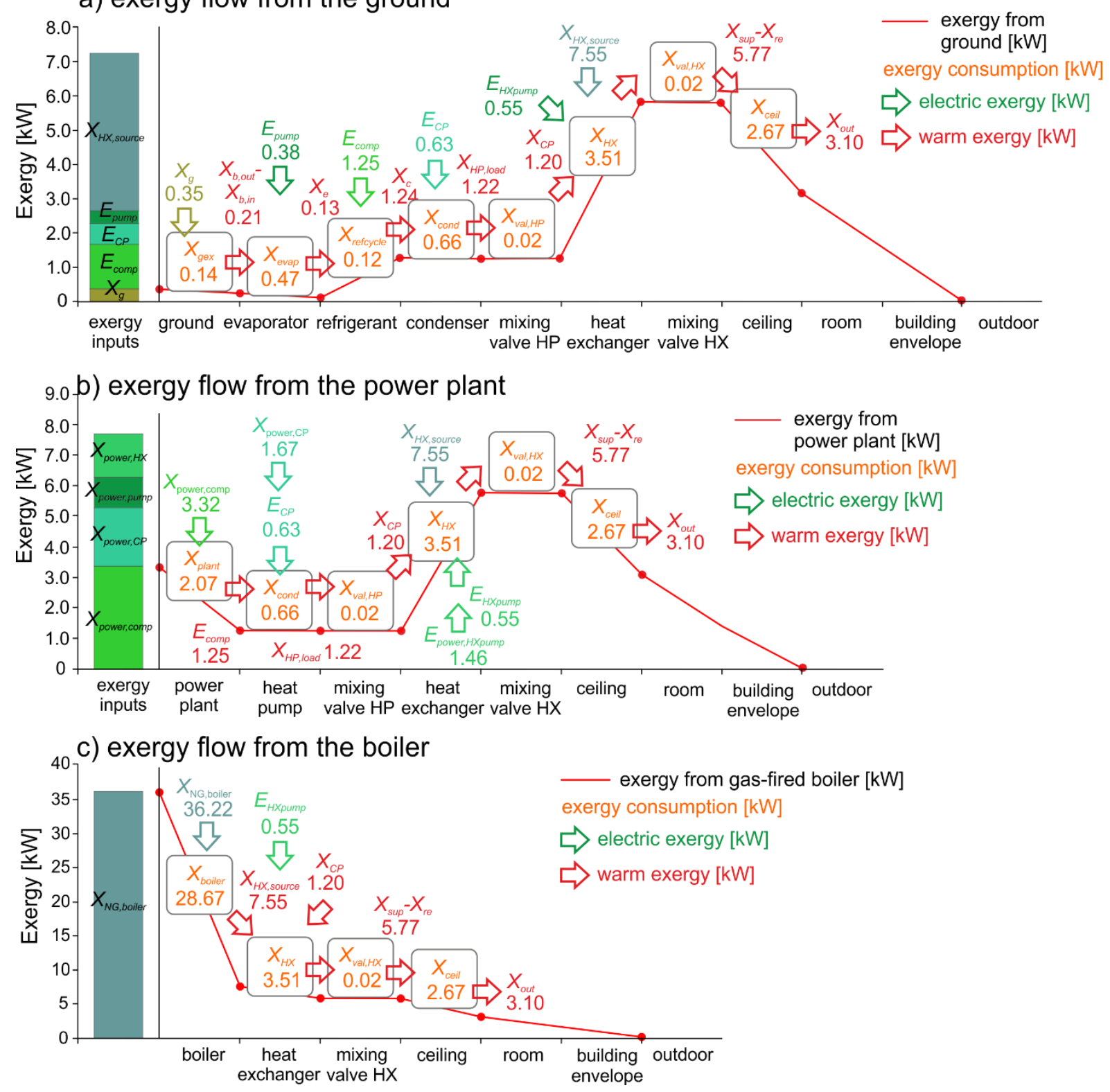

Figure 4: Exergy flow diagrams for the system in heating mode: a) from the ground to the outdoor environment, b) from the power plant to the outdoor environment and c) from the natural gas to the outdoor environment. Exergy flows are shown for the base values as solid lines and the additional exergy input from the electronic auxiliary components as dashed lines, respectively. Exergy values in $\mathrm{kW}$ for the individual system components in heating mode with red arrows indicating warm exergy flows and green arrows electricity input to the system. Exergy consumptions are labelled in orange.

The comparison of the exergy extracted from the ground $X_{g}$ and the exergy input from the heat

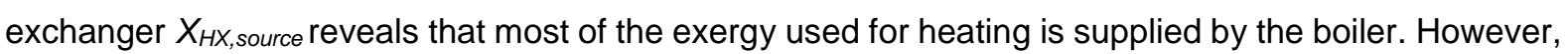
this small amount of $X_{g}$ consists of natural exergy, which is freely available and not generated by means 
of fossil fuels. Furthermore, it can be extracted in the immediate environment of the building, which means that losses due to transmission and distribution are minimal compared to the exergy input from fossil fuels through power plant (Figure 4b).

The exergy flow from a remote power plant, shown in figure $4 \mathrm{~b}$, represents the exergy input from natural gas converted into electric energy that is needed to drive the electronic components of the system (eqs. 48-51). Despite being named 'auxiliary components' here and in other studies, these electronic components play a vital role in the energy supply system. They consume exergy in the form of electricity in order to move the carrier of the exergy, water in our case, through the system from the heat source to heat sink. Figure $4 b$ shows that a significant portion of the exergy required to provide the electricity for the compressor is lost during generation and transmission in the power plant component. However, this exergy consumption is less than the consumption in the heat exchanger and the ceiling. This highlights the dominant role of the components related to the hybrid system for overall exergy consumption, as electricity generation outside the energy supply system is typically found to be the component with the highest consumption rates in low-exergy supply systems [31, 33, 34]. An even higher exergy consumption is identified in the boiler subsystem (Figure 4c), which is in accordance with the findings from previous studies on conventional heating systems [18, 34].

\subsection{Exergy values for the system component in cooling mode}

The results for the exergy flow and consumption values for each component of the system in cooling mode are shown in Figure 5 in the same manner as for heating mode. The steepest gradient of the exergy flow is found here for the components of the heat pump (Figure 5a), which indicates that a significant amount of exergy is consumed in these components. The input from the ground $X_{g}$ is more than twice as large as in heating mode, but still rather small compared to the exergy input from the electronic components. The amount of exergy delivered to the room is also much smaller than in heating mode, because the temperature spread between supply $\left(T_{\text {sup }}\right)$ and return $\left(T_{r e}\right)$ is smaller, as the cooling demand $Q_{\text {out }}$ is much smaller. The gradient of the exergy flow from the power plan is quite steep (Figure $5 b)$, and exergy consumption is again most dominant in the power plant and transmission grid component outside of the energy supply system of the building.

Compared to the cooling system investigated by Li et al. [38] our study yields higher exergy input and consumption values associated with a similar amount of cool exergy output. The exergy input is higher in our system because of a higher electricity demand for the auxiliary components and a larger natural exergy input, $X_{g}$, caused by a wider temperature spread in our BHE subsystem. The system investigated by Li et al. [38] is an air-based system, where the supplied air is directly cooled at the evaporator of the heat pump. Thus, no additional components, such as mixing valves or radiant ceiling, are needed on the load side of the system, apart from a ventilation fan. The exergy consumption is higher within our system due to wider temperature differences across individual components in our study. Also, in $\mathrm{Li}$ et al. [38] the temperature spread between the evaporator and the room is smaller, as no separate carrier fluid, such as water in our system, is needed for the delivery of cool exergy. 


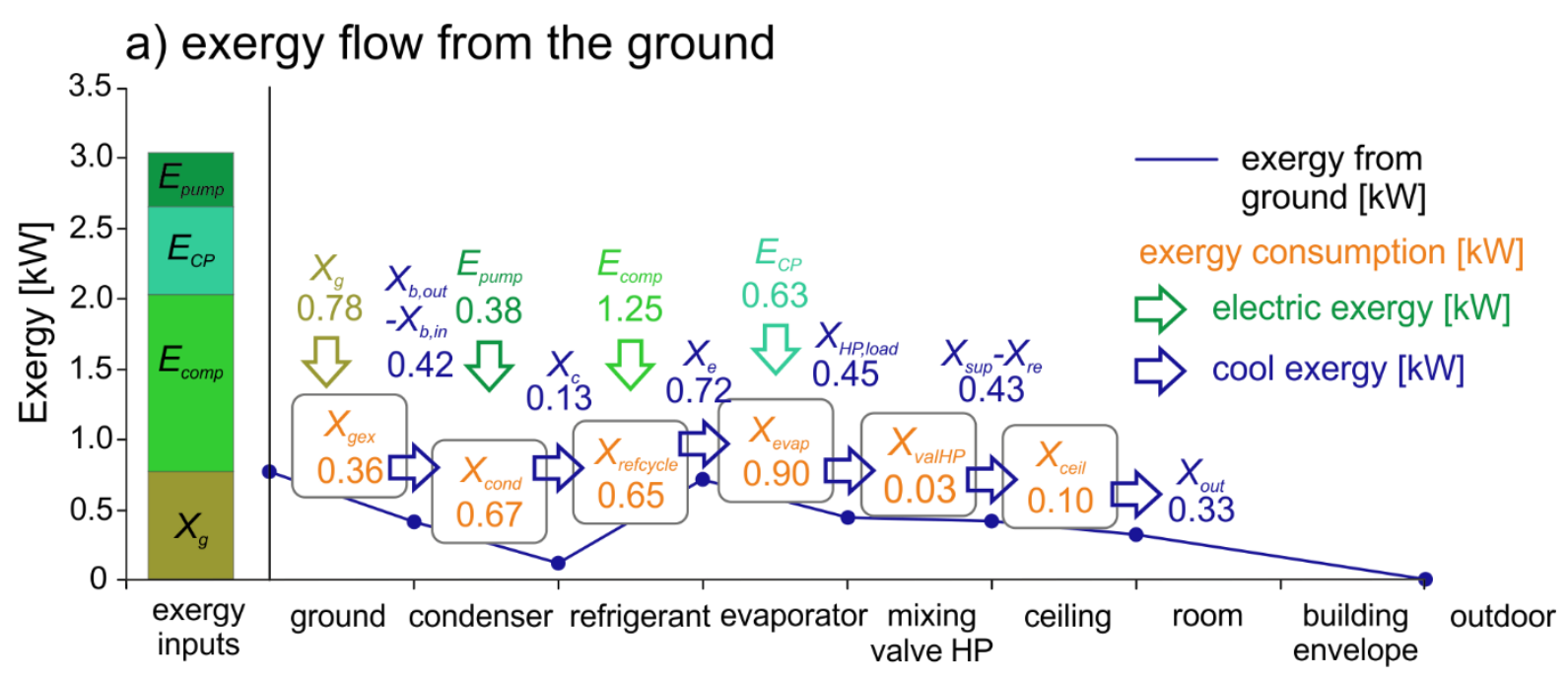

b) exergy flow from the power plant

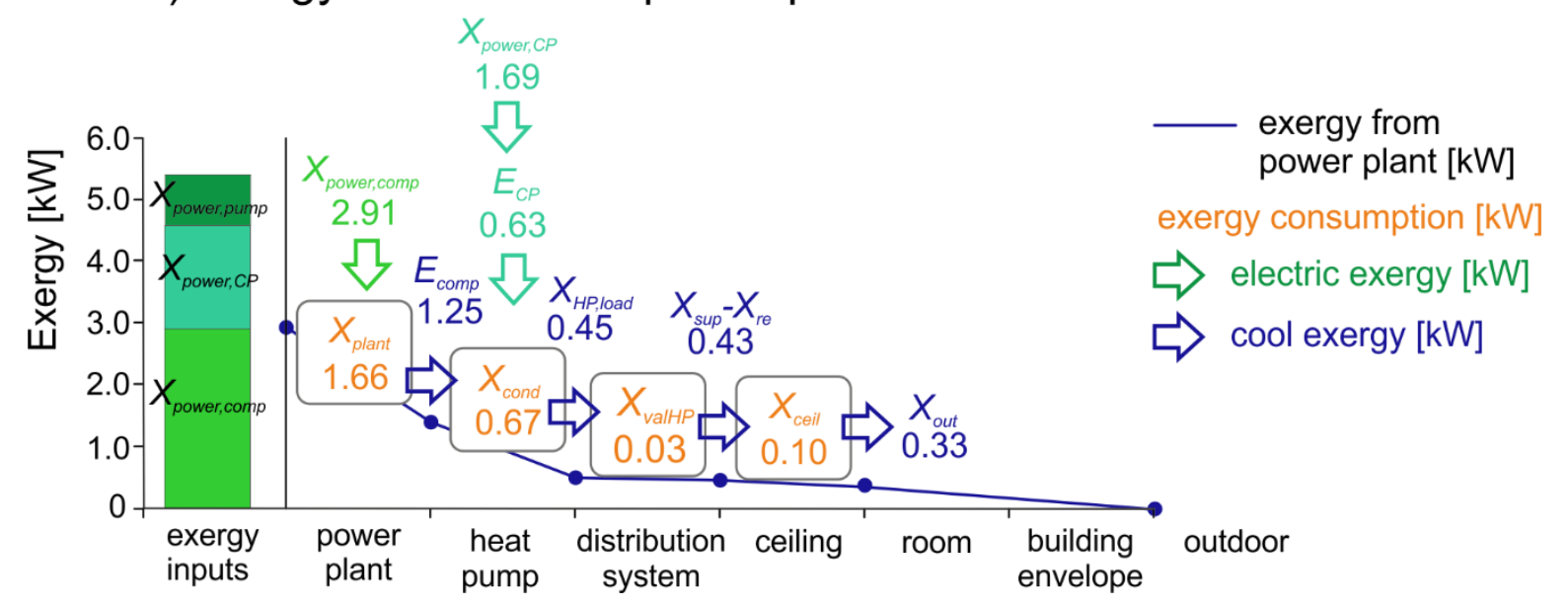

Figure 5: Exergy flow diagrams for the system in cooling mode: a) from the ground to the outdoor environment and $b$ ) from the power plant to the outdoor environment. Exergy flows are shown for the base values as solid lines and the additional exergy input from the electronic auxiliary components as dashed lines, respectively. Exergy values in $\mathrm{kW}$ for the individual system components in cooling mode with blue arrows indicating cool exergy flows and green arrows electricity input to the system. Exergy consumptions are labelled in orange.

\subsection{System performance in heating and cooling mode}

Table 2 lists the sums of exergy input, consumption and output values for the whole system in heating and cooling mode. A comparison of the exergy values in both modes reveals the following significant differences:

(a) The exergy input in heating mode is more than three times larger than in cooling mode, which is mostly supplied by the boiler through the heat exchanger.

(b) The exergy output of the system is much larger in heating mode due to the large temperature difference between the heating fluid, $T_{\text {sup }}$, and the room set point temperature, $T_{\text {in }}$. This is due to the characteristics of the radiant ceiling in heating mode.

(c) Consequently, exergy consumption is also larger in heating than in cooling mode, due to the enormous consumption in the heat exchanger and the large consumption in the radiant ceiling, which is found to be 26 times higher than in cooling mode. On the contrary, there is less exergy consumed 
by the ground heat exchanger and the heat pump than in cooling mode, because of the smaller temperature spread.

Previous studies that compared the exergy performance of different subsystem of energy supply systems in both heating and cooling mode found less significant differences (up to a factor of 10) between the two operational modes, when the exploited energy and exergy sources are the same, i.e. either the ground, air or electricity [22, 41].

Table 2: Exergy values resulting from the analysis of the studio system in cooling and heating mode applying the design temperature, flow rate values and electricity consumption of auxiliary components from Table 1.

\begin{tabular}{lcc}
\hline & cooling mode $[\mathrm{kW}]$ & heating mode $[\mathrm{kW}]$ \\
\hline total exergy inputs & 3.04 & 10.71 \\
total exergy consumption & 2.71 & 7.62 \\
exergy output & 0.33 & 3.09 \\
\hline
\end{tabular}

The significant differences in exergy input, consumption and output values for the system in heating and cooling modes naturally affect the exergy efficiencies used to characterize the performance of the system (eqs.43-48) (Table 3). The non-natural exergy efficiency of the system $\eta_{s 1}$ in heating mode is twice as high as in cooling mode, which is because of the significant thermal exergy input through the boiler (Figure 4a). The natural exergy $\eta_{s 2}$ efficiency is several times higher in cooling mode than in heating mode due to the large amount of exergy originating from fossil fuel in the boiler in heating mode, while in cooling mode a quarter of the exergy available for space cooling is provided by the natural, renewable energy source. The true system efficiency $\eta_{s 3}$ in heating mode, which considers all natural and fossil fuel-based exergy inputs, is almost identical to the system exergy efficiency, as the natural exergy input is relatively small. The system in cooling mode on the other hand exhibits a lower true system efficiency, because the natural exergy content represents a significant fraction of the exergy inputs.

Table 3: Exergy efficiency values from the analysis of the studio system in cooling and heating mode applying the design temperature and flow rate values from Table 1.

\begin{tabular}{lcc}
\hline & cooling mode [\%] & heating mode [\%] \\
\hline system exergy efficiency $\eta_{S 1}$ & 14.6 & 29.8 \\
system natural exergy efficiency $\eta_{S 2}$ & 25.6 & 3.3 \\
true system efficiency $\eta_{S 3}$ & 10.9 & 28.8 \\
\hline system COP & 10.3 & 7.3 \\
\hline overall exergy efficiency $\eta_{1}$ & 6.0 & 47.3 \\
overall natural exergy efficiency $\eta_{2}$ & 12.40 & 5.1 \\
true overall exergy efficiency $\eta_{3}$ & 5.3 & 44.9 \\
\hline
\end{tabular}

The COP value of the heat pump is slightly higher in cooling mode, which is due to the larger difference between $T_{c}$ and $T_{e}$ needed in heating mode. The overall performance indicators $\left(\eta_{1}, \eta_{2}, \eta_{3}\right)$ allow an assessment of the efficiencies beyond the boundaries of the building by taking into account the efficiency of power generation for the electronic components. In cooling mode, these overall efficiencies 
are generally small, as the contribution of electric energy to the exergy output is relatively large (Figure $5 b)$. Likewise, the relatively small impact of electric exergy compared to the heat input from the boiler, results in larger overall exergy efficiency ratios for heating mode.

Kazanci et al. [39] achieved a significantly higher overall natural exergy efficiency of $53.2 \%$ by using two cold sources, the ground and a shaded crawl-space. In comparison to the study by Li et al. [38] our system requires larger exergy inputs to deliver the same amount of exergy, which results in lower exergy efficiencies and COP values in our study. The overall exergy efficiency $\eta_{1}$ for their system is also higher $(18.0 \%)$, suggesting that the relative power demand of the electric system components is less than in our study. Overall, the comparison with exergy efficiency values from other studies raises the question about potential improvements to the system investigated in our study regarding exergy efficiency, which will be investigated in next section.

\subsection{Scenario analysis for performance improvement}

To demonstrate how the derived exergy model could be used during the design stage or during energy retrofit planning to investigate the effect of different options on the system performance, we conduct a scenario analysis for different improvement measures. We evaluate the steady-state exergy performance of the hybrid GSHP system of the Studio room under the design conditions for the following scenarios: a) improvement of the heating and cooling system by reducing the electricity demand of electrical equipment in the model, b) improvement of the system by changing the temperature level of the energy system, while keeping the absolute temperature difference between supply and return flow fixed and c) improvement of the building envelope by reducing the output energy required for space heating and cooling by lowering the temperature difference between the supply and return flow in the model.

\subsubsection{Reduction of the power demand of the supply system}

The assumption of reducing the exergy input from electricity consumption of the auxiliary components is based on the possibility of replacing the existing electrical equipment with components that have a higher efficiency (power to electricity ratio). Therefore, we investigate the effect on the exergy balance and exergy performance for reduction in power demand by 10,20 and $30 \%$ of the original value for heating and cooling mode, respectively.

For the system operating in cooling mode, Figure 6a shows a decrease in exergy input and consumption with decreasing power demand, and a very slight increase in exergy output from 0.33 to $0.35 \mathrm{~kW}$, due to the more prominent decrease in consumption than in exergy input. Reduction in power demand for auxiliary components increases system efficiency and COP. The influence on overall efficiency is less, because exergy consumption outside the system during power generation and distribution are more dominant, which reduces the relative impact of the auxiliary electricity demand. Assuming a reduction in power demand of $30 \%$ the system efficiency could be increased by approx. $4-8 \%$, while the overall performance efficiency could be improved by $3-4 \%$.

In heating mode, the same reduction in electricity demand yields a smaller decrease in exergy consumption (Figure $6 \mathrm{c}$ ), and a potential increase in system efficiency of approx. 0.1-1.0\% and a more prominent increase of approx. 1-7\% for the overall efficiency (Figure 6d). The opposite effect on overall 
efficiency between heating and cooling mode can be explained by the significant influence of the thermal exergy delivered through the heat exchanger.

However, it must be remembered that the electricity consumption of the components also affects the energy balance of the system so that a reduction in power demand has not only positive effects, but also reduces the exergy input to the system. This is particularly true for the power demand of the compressor, $E_{c o m p}$, which has the highest electricity demand of the auxiliary components. The increase in system performance levels out rapidly at about 30\% reduction for heating mode (Figure $6 \mathrm{~d}$ ), where exergy consumption in the heat pump $\left(X_{\text {refcycle }}\right)$ was low for the base case (Figure $\left.4 a\right)$. With less exergy input in form of $E_{\text {comp }}$ and the same output required to provide heating, the consumption cannot be reduced much further, i.e. no further increase in efficiency is possible, without any additional system changes.

From an economic point of view the reduction in power demand is an effective option, as it will significantly reduce the operational costs of the system in cooling mode, where electricity costs are the only cost factor. The overall costs reduction for heating mode will need to take into account the additional costs for the gas-fired boiler, which will depend on the actual gas consumption under operation. However, the installation costs of new equipment with higher efficiencies have to be considered as well.

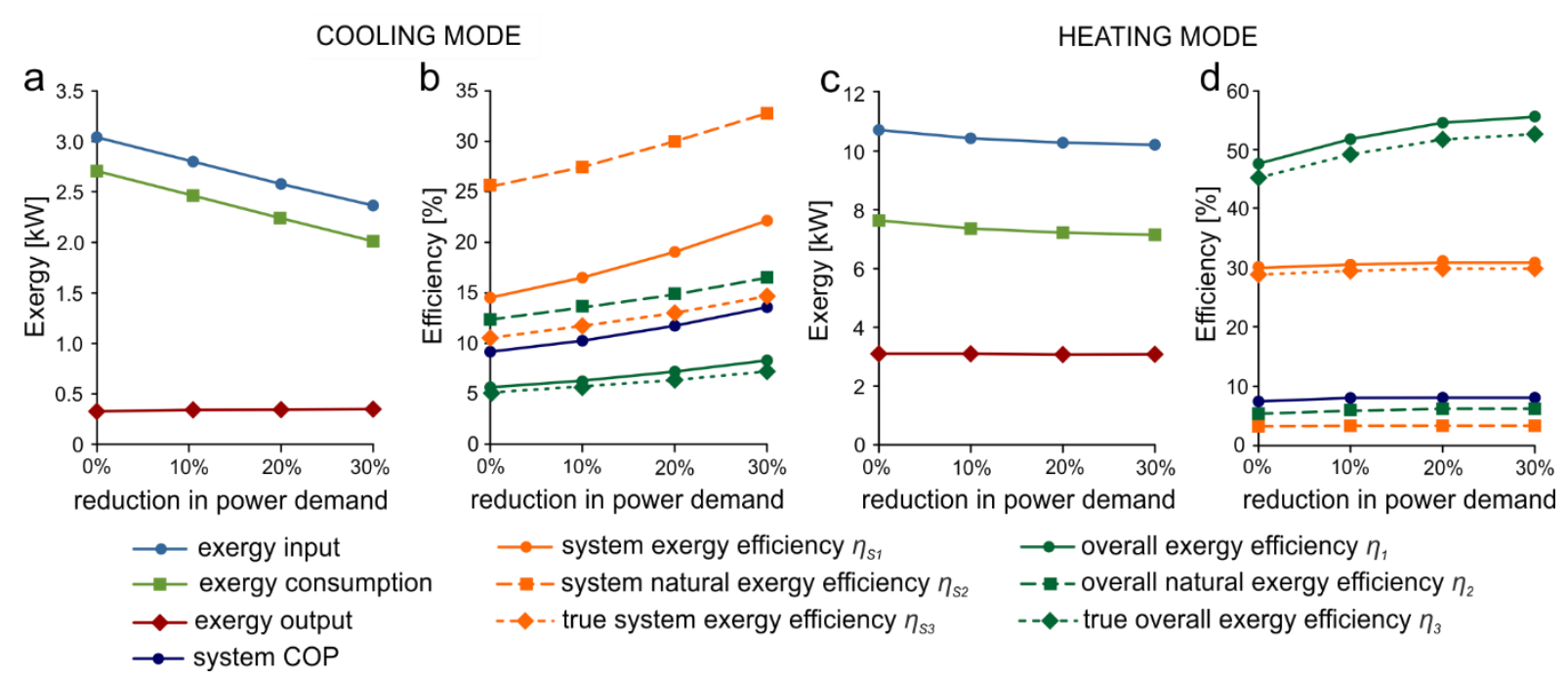

Figure 6: a, c) Total exergy input, output and consumption, and b, d) performance indicators for different values of the reduction in energy demand of auxiliary components for the system in cooling mode (a, b) and heating mode (c, d).

\subsubsection{Altering the temperature level of the supply system}

Another option for improving the system performance is changing the temperature at which the system operates. As discussed above, a smaller temperature difference between the individual subsystems significantly influences the exergy consumption and a reduction could thus improve the exergy efficiency. Therefore, we analyse the effect of changing the temperature level of the cooling and heating circuit, respectively, while the temperature difference and the amount of supplied energy is kept constant. 
For the system in cooling mode it is revealed that changing the temperature level of the cooling circuit has no effect on the overall exergy input, consumption or output, and accordingly no effect on the exergy efficiency ratios (Figure 7a). As expected the exergy consumption in the radiant ceiling, $X_{c e i l}$, decreases as $T_{\text {sup }}$ approaches $T_{\text {in }}$ at $294 \mathrm{~K}$. However, at the same time the exergy consumption in the evaporator increases by exactly the same amount, because the temperature spread between the cooling circuit and the refrigerant cycle increases. Adapting the temperature spread across the heat pump components accordingly might be an appealing solution, but the temperature of the ground, which is the only source of the cool exergy, is ultimately fixed at a given temperature $\left(T_{g}\right)$, which corresponds not only to the assumed design conditions, but also to specific subsurface conditions on-site.
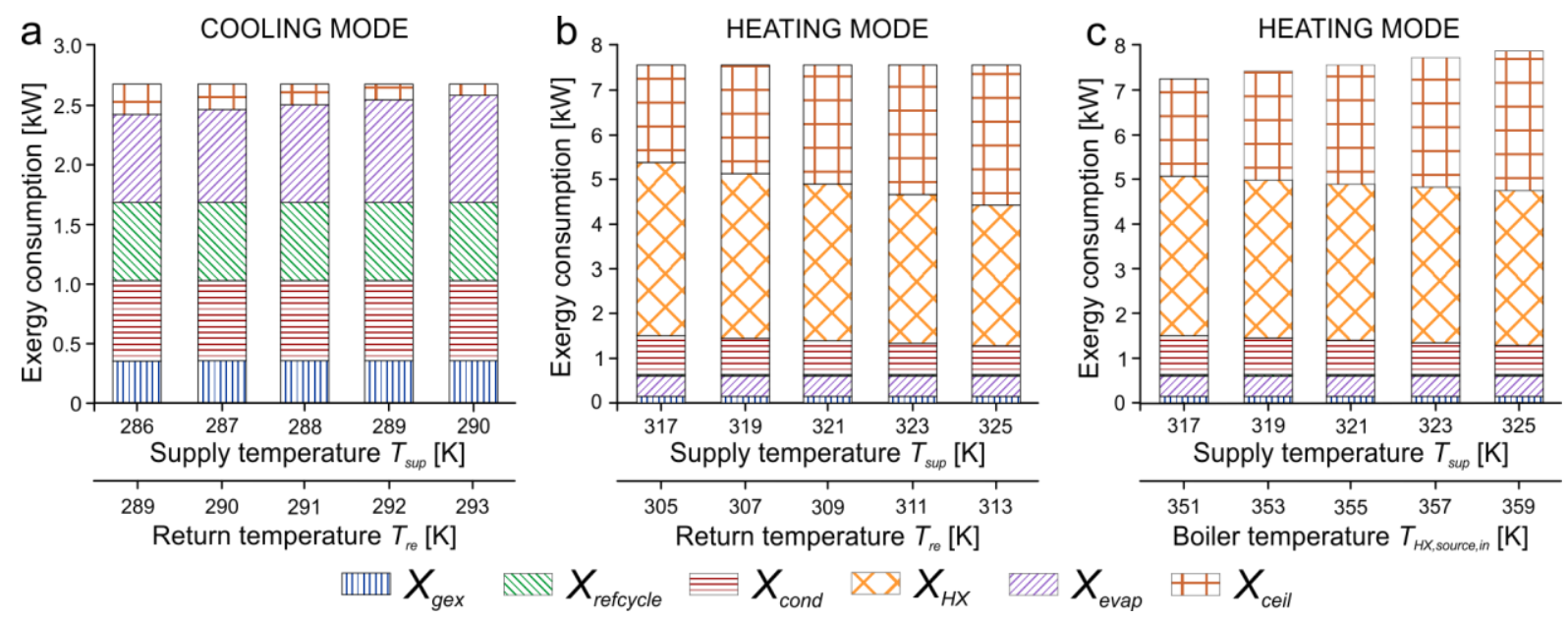

Figure 7: Detailed exergy consumption due to variation of the supply and return temperature (with constant temperature difference and constant energy output) for the system in (a) cooling, (b) heating mode, and (c) heating mode with the temperature of the boiler and heat exchanger source side being varied by $2 \mathrm{~K}$, respectively. The supply temperature of $288 \mathrm{~K}$ in cooling mode, $321 \mathrm{~K}$ in heating mode, and $T_{H X, \text { source, in }}$ of $355 \mathrm{~K}$ correspond to the design values of the system. The return temperature is in cooling mode always $3 \mathrm{~K}$ higher and for heating $12 \mathrm{~K}$ lower than supply temperature $T_{\text {sup. }}$.

The same effect can be seen for heating mode (Figure $7 b$ ), as the reduction in exergy consumption in the ceiling, $X_{\text {ceill, }}$ with lower heating temperatures is compensated by an increase in consumption, $X_{H X}$, in the heat exchanger. However, in heating mode, the hybrid system uses two different sources of warm exergy: the ground, which comprises a fixed boundary, and the heat exchanger, which is supplied by a gas-fired boiler. Figure 7c shows the resulting exergy consumptions when the temperature level of the boiler circuit is also varied by $2 \mathrm{~K}$. Under these conditions, an increase in $X_{H X}$ still compensates a portion of the decrease in $X_{\text {ceil, }}$, but overall there is a decrease in the exergy consumption with decreasing system temperatures. The system overall $\left(\eta_{s_{1}}\right)$ and natural $\left(\eta_{s_{2}}\right)$ exergy efficiency indicators show a minor improvement of approx. $2 \%$ with decreasing temperature level (not shown), while the overall performance indicators still yield no improvement, because changing the temperature level does not affect the exergy output or the power demand of the system. This lack of overall improvement would make this measure a less effective option for increasing exergy performance than the reduction of energy demand. 
Also, the efficiency of the condensing boiler will also be affected by changes in the boiler supply and return temperatures, as well as the overall heat losses. Thus, a more comprehensive analysis of energy and exergy efficiency would be needed to explore the full range of the consequences of such system adaptions. Another option would be to change the indoor set point temperature, which would affect the overall temperature spread across the system, but at the same time such changes might conflict with the building use or negatively impact the thermal comfort. The changes investigated in this scenario have no economic consequences for the system operating in cooling mode, as the power demand for the auxiliary components, which cause the operational costs, remains constant. For the system in heating mode the operational costs depend on the gas consumption in the boiler, and accordingly not only on the amount of energy supplied by the boiler, but also on its efficiency, which was not investigated in this study.

\subsubsection{Reduction of the space energy demand}

We also explore the scenario of improving the building envelope (for instance by increasing the thermal insulation), which results in a lower energy demand to maintain a certain indoor temperature. In our exergy model a lower energy demand can be emulated by reducing the difference, $\Delta T$, between supply and return temperatures of the heating and cooling circuit. In heating mode, the amount of energy and exergy from the GSHP is not varied with the varying $\Delta T$ so that the amount of additional (or reduced) energy required is allocated to heat from the fossil fuel-based boiler. It seems natural to do so in this theoretical analysis, as an increase of the capacity of the heat pump will be limited by the thermal conditions in the subsurface (as stated above), while the boiler component is more likely to have a certain operational reserve.

As expected, the values of the overall exergy inputs, consumptions and output show an increasing trend with increasing $\Delta T$ (Figure 8), as lower temperature differences result in lower exergy outputs and consumption, and also in a smaller exergy input from the ground or the heat exchanger, respectively. Close inspection of Figure $8 \mathrm{a}$ and $\mathrm{b}$ shows that the exergy input increases more rapidly than the exergy output leading to an increase in efficiency (Figure $8 c$ and d), indicating that the system is more efficient for higher energy demands. Similar to Figure 6 this trend is more pronounced for system performance indicators and the COP for cooling mode (Figure 8c), while in heating mode the increase in overall performance indicators is more prominent (Figure 8d), which is linked to the dominant amount of exergy input from electricity and natural gas in heating mode. A comparison of the relative changes with regard to the design values per $1 \mathrm{Kelvin}$ change in $\Delta T$ and averaged over the full range of explored $\Delta T$ reveals that, while the impact on exergy values is similar for heating and cooling mode (Figure 8a and b), the change in exergy efficiency is more significant in cooling than in heating mode (Figure $8 \mathrm{c}$ and d). This indicates that this measure is more effective for improving cooling performance than for heating.

The individual exergy consumption terms per component reveal that in cooling mode the exergy consumed by the ceiling, evaporator, condenser and ground increase as more energy is required for cooling (Figure 8e). The simultaneous decrease in $X_{\text {refcycle }}$ compensates most of the increase in other components and reflects the increase in the COP value, indicating that the heat pump is more efficient for larger amounts of transferred energy. The changes in the exergy consumption in heating mode are mainly related to changes in $X_{c e i l}$ and $X_{H X}$, which reflect the increasing amount of energy from the boiler 
transferred through the heat exchanger and the ceiling (Figure 8f). This reflects the counter acting effect of system improvement and simultaneous increase in absolute exergy consumption for higher heating and cooling demands.

From an economic perspective, a reduction in heating and cooling demand obviously leads to lower operational costs, in particular due to the lower gas demand for heating with the hybrid system. However, potential energy savings need to be balanced with the costs of better insulation under consideration of a reasonable payback period, which will depend significantly on the building and the specific type of building envelope improvement.
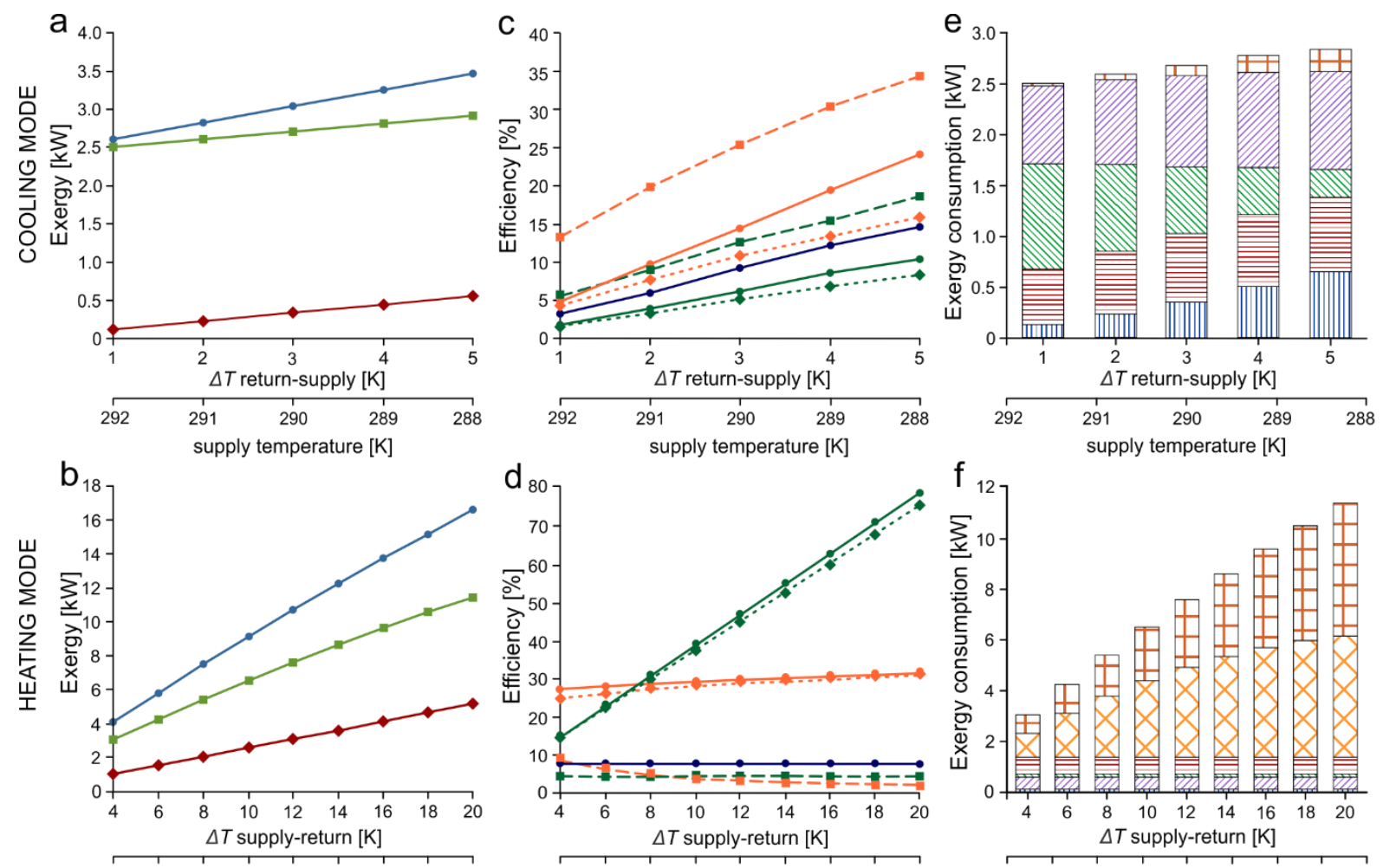

$\begin{array}{lllllllll}313 & 315 & 317 & 319 & 321 & 323 & 325 & 327 & 329\end{array}$

$\begin{array}{lllllllll}313 & 315 & 317 & 319 & 321 & 323 & 325 & 327 & 329\end{array}$ supply temperature $[\mathrm{K}]$

$\multimap$ exergy input $\rightarrow$ exergy consumption $\multimap$ exergy output $\rightarrow$ system COP

$\longrightarrow$ system exergy efficiency $\eta_{s 1}$

$\longrightarrow$ overall exergy efficiency $\eta_{1}$

- - - system natural exergy efficiency $\eta_{s 2}$

- - - overall natural exergy efficiency $\eta_{2}$

- $\rightarrow$ - - true overall exergy efficiency $\eta_{3}$

$\begin{array}{lllllllll}313 & 315 & 317 & 319 & 321 & 323 & 325 & 327 & 329\end{array}$ supply temperature $[\mathrm{K}]$

$$
\begin{aligned}
& \text { ㅁाIIIII } X_{\text {gex }} \equiv X_{\text {cond }}
\end{aligned}
$$

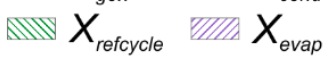

$$
\begin{aligned}
& \square \searrow X_{H X} \boxplus X_{\text {ceil }}
\end{aligned}
$$

Figure 8: $a, b$ ) total exergy input, output and consumption, c, d) performance indicators and e, f) exergy consumption due to variation of the temperature difference $\Delta T$ between supply and return flow for the system in cooling and heating mode. The supply temperature of $288 \mathrm{~K}$ in cooling mode and $321 \mathrm{~K}$ in heating mode correspond to the design values of the system. Heating and cooling return temperatures are kept at their design values of $293 \mathrm{~K}$ and $309 \mathrm{~K}$, respectively.

\section{Conclusions}

Examination of a novel thermodynamic model, which takes into account warm and cool exergy, of a hybrid GSHP system with a supplementary boiler enables an in-depth assessment of the exergy performance of the individual system components, such as the heat exchanger and the radiant ceiling. 
A detailed comparison of the exergy values in heating and cooling for the first time reveals significant differences regarding the components that attribute most to the overall exergy consumption in the system in different modes, and considerable disparities regarding the efficiency of the system compared to previously studied systems.

While in cooling mode exergy consumption is relatively low $(2.71 \mathrm{~kW})$, as typical for these systems, considerable exergy consumption occurs in heating mode in the subsystem with the additional heat source $(7.62 \mathrm{~kW})$. The required mixing valves in this subsystem were found to contribute only very little to the overall exergy consumption, yet they still represent non-negligible components that need to be considered in such detailed analyses. The highest exergy consumption is found in the heat exchanger component between the heating loop and the boiler, which contributes ca. 50\% to the total system consumption. Also, exergy consumption in the radiant ceiling in heating mode was found to be a significant source of irreversibility, and considerably higher than in cooling mode or previous studies with radiant heating systems. These findings highlight the negative impact of a large temperature spread across individual components on the overall exergy efficiency, and suggest that the use of a conventional, high-temperature heat source in combination with a GSHP system and a radiant ceiling may not be favourable from an exergetic point of view.

Overall, exergy inputs from the boiler and electricity demand for the auxiliary equipment, such as pumps, are much larger than the natural exergy input from the ground in both heating and cooling mode, and suggest space for the improvement of system design. However, while reducing the electricity demand of the auxiliary components results indeed in an improved exergy efficiency, it simultaneously affects the energy balance and thus reduces the amount of exergy available in the system. A fact that has not been highlighted previously. The comparison of different exergy performance indicators reveals that though heating is in itself efficient, the natural energy source is exploited less efficiently than in cooling mode. It also emphasizes the usefulness of using all six different metrics in conjunction, which are typically not applied at the same time, as the improvement measures can cause very diverse changes in the system performance at different locations or on different levels. However, adapting the operational temperature level of the system in heating mode, while keeping the supplied amount of energy constant, has no effect on the system performance, as there is no possibility in this type of system to change the overall temperature difference between thermal energy source and sink.

The most promising option was found to be improved thermal insulation of the building envelope, as it increases the exergy efficiency by reducing the heating and cooling demand. This indicates that measures to improve the exergy performance of an energy supply system should focus on improvements of the building envelope, rather than operational changes to the system, such as changes in temperatures or electricity demands. However, the absolute values for changes in exergy efficiency obtained in this study are only valid for this particular system under steady-state, design conditions. Changes in any of these conditions, such as changes in flow rates or temperature values, will naturally affect the model outcome for system exergy values and exergy efficiencies etc. Thus, further research is needed to evaluate the influence of variable boundary and system conditions, such as ground temperature, evaporation and condensing temperatures and to explore the effect of alternative choices for the reference temperature. In addition, further steps are required to adapt the steady-state model to 
allow dynamic evaluation of exergy efficiency in order to enable analysis of the system performance under real operational conditions.

\section{Acknowledgements}

This study was conducted as part of the 'Bayesian Building Energy Management (B.bem)' project funded by the Engineering and Physical Sciences Research Council of the United Kingdom (EPSRC reference: EP/L024454/1).

\section{Appendix}

\section{A: Derivation of the governing equation for exergy content}

The general equation for exergy $X$ contained in a closed system according to Shukuya [1] can be expressed in form of:

$$
X=\int_{0}^{X} d X=\int_{U_{0}}^{U} d U+P_{0} \int_{V_{0}}^{V} d V-T_{0} \int_{S_{0}}^{S} d S=\left(U-U_{0}\right)+P_{0}\left(V-V_{0}\right)-T_{0}\left(S-S_{0}\right)
$$

Where $U$ represents the internal energy of the system, $P_{0}$ the reference (environmental) pressure, $V$ the volume of the system, $T_{0}$ the reference temperature, and $S$ the entropy.

For the exergy contained in a certain volume of water, $X$, assuming that inside and outside pressure are equal and constant, eq. A1 can be rewritten (eq. A.2) [1]:

$$
X=\left(U_{w}+P_{w} V_{r}\right)-\left(U_{0}+P_{0} V_{0}\right)-T_{0}\left(S_{w}-S_{0}\right)
$$

With enthalpy, $H$, being defined as $H=U+P V$, eq. A.2 can be rewritten as (eq. A.3) [1]:

$$
X=\left(H_{w}-H_{0}\right)-T_{0}\left(S_{w}-S_{0}\right)
$$

An increase in enthalpy, $d H_{w}$, under the condition of constant pressure equals the infinitesimal heat flow, $\delta Q$, which relates to an increase in the internal temperature, $d T_{w}$, with a constant heat capacity, $c_{w}$, and density, $\rho_{w}$, of the water (A.4) [1]:

$$
d H_{w}=d U_{w}+P_{0} d V_{w}=\delta Q=c_{w} \rho_{w} V_{w} d T_{w}
$$

As an increase in entropy, $d S_{w}$, equals $d Q / T_{w}$, eq. A.4 can be written as (eq. A.5) [1]:

$$
d S_{w}=c_{w} \rho_{w} V_{w} \frac{d T_{w}}{T_{w}}
$$

Integration of $d H_{w}$ and $d S_{w}$ from $T_{0}$ to $T$, and using eqs. A.4 and A.5, leads to the formula of thermal exergy, $X_{w}$, contained by the fluid entering (or flowing out of) a system component per unit time interval (A.6):

$$
X_{w}=c_{w} \rho_{w} v_{w}\left\{\left(T_{w}-T_{0}\right)-T_{0} \ln \frac{T_{w}}{T_{0}}\right\}
$$

Where $v_{w}$ represents the volumetric mass flow of the water in the system component in $\mathrm{m}^{3} / \mathrm{s}$. 


\section{B: Exergy equations for the system in heating mode}

In heating mode, the ground heat exchanger is used to heat the BHE circulation fluid, which enters the evaporator side of the heat pump. In the expansion valve a distinct pressure drop leads to the evaporation of the liquid refrigerant, which then enters the evaporator side of the heat pump at a low temperature and evaporates by receiving heat from the heat carrier fluid in the BHE. After the compressor in the heat pump, the refrigerant enters the condenser side of the heat pump, where the compressed, but still vapour-state refrigerant fluid condenses and releases heat into the heating circulation fluid. A fraction of the heating fluid enters the heat exchanger connected to a boiler circulation loop, before being mixed with the bypassed flow fluid in the mixing valve HX. The merged fluid leaving the mixing valve represents the heating supply fluid entering the radiant ceiling component. The equations defining the energy and exergy balances and contents of the individual subsystems are set up using the general equation for warm exergy (eq. 1).

\section{Borehole heat exchanger}

The energy and exergy balance equations for the BHE circulation fluid and the ground (eqs. 6 and 7) can be defined according to the general energy and exergy balance equations (eqs. 3 and 5).

$$
\begin{aligned}
& c_{b} m_{b}\left(T_{b, \text { in }}-T_{0}\right)+Q_{g}=c_{b} m_{b}\left(T_{b, \text { out }}-T_{0}\right) \\
& X_{b, \text { in }}+X_{g}-X_{\text {gex }}=X_{b, \text { out }}
\end{aligned}
$$

The energy exchanged with the ground, $Q_{g}$, in heating mode is directed towards the heat carrier fluid in the BHE. The terms $c_{b} m_{b}\left(T_{b, \text { in }}-T_{0}\right)$ and $c_{b} m_{b}\left(T_{b, \text { out }}-T_{0}\right)$ quantify the amount of thermal energy contained in the BHE inlet and outlet flow, respectively, specified by the mass flow rate $m_{b}$ and the corresponding temperatures, $T_{b \text {,int }}$ and $T_{b \text {,out }}$. The exergy extracted from the ground, $X_{g}$, comprises warm exergy and can be defined according to eq. A.9 based on the general equation for warm exergy (eq. 1). The exergy balance in eq. A.8 has two input terms, namely the exergy of the geothermal return flow $X_{b, i n}$ (eq. A.11) and the exergy exchanged with the ground $X_{g}$, while $X_{g e x}$ is the exergy consumption during heat exchange with the ground, and $X_{b, \text { out }}$ is the output exergy comprised in the BHE outlet flow (eq. A.10).

$$
\begin{aligned}
& X_{g}=\left(1-\frac{T_{0}}{T_{g}}\right)\left(Q_{g}\right) \\
& X_{b, \text { out }}=c_{b} m_{b}\left\{\left(T_{b, \text { out }}-T_{0}\right)-T_{0} \ln \frac{T_{b, \text { out }}}{T_{0}}\right\} \\
& X_{b, \text { in }}=c_{b} m_{b}\left\{\left(T_{b, \text { in }}-T_{0}\right)-T_{0} \ln \frac{T_{b, \text { in }}}{T_{0}}\right\}
\end{aligned}
$$

\section{Evaporator of the heat pump}

The energy balance (eq. A.12) of the evaporator side of the heat pump in heating mode also considers the electricity needed to operate the BHE pump $E_{\text {pump }}$ as an energy input. Likewise, the exergy balance (eq.A.13) has two input terms for the exergy content of the geothermal fluid $X_{b, \text { out }}$ (eq. A.10) and the exergy input by $E_{\text {pump }}$, as well as two output terms for the exergy of the geothermal return flow $\mathrm{X}_{\mathrm{b} \text {,in }}$ (eq. 
A.11) and the exergy output into the refrigerant $X_{e}$ (eq. A.14), which can be calculated based on the energy exchanged with the refrigerant at the evaporator $Q_{e}$. In addition, the exergy consumption in the evaporator is quantified by $X_{\text {evap. }}$. The overall energy balance of the borehole heat exchanger loop is given by eq. A.15.

$$
\begin{aligned}
& E_{\text {pump }}+c_{b} m_{b}\left(T_{b, \text { out }}-T_{0}\right)=c_{b} m_{b}\left(T_{b, \text { in }}-T_{0}\right)+Q_{e} \\
& E_{\text {pump }}+X_{b, \text { out }}-X_{\text {evap }}=X_{b, \text { in }}+X_{e} \\
& X_{e}=\left(1-\frac{T_{0}}{T_{e}}\right) Q_{e} \\
& E_{\text {pump }}+Q_{g}=Q_{e}
\end{aligned}
$$

\section{Refrigerant cycle}

The energy and exergy balance equations (eqs. A.16, A.17) of the refrigerant loop in the heat pump can be defined based on the corresponding input and output terms and accounting for the electricity demand of the compressor of the heat pump $E_{c o m p}$ and the exergy consumption in the refrigerant cycle $X_{\text {refcycle }}$ [38].

$$
\begin{aligned}
& E_{\text {comp }}+Q_{e}=Q_{c} \\
& E_{\text {comp }}+X_{e}-X_{\text {refcycle }}=X_{c}
\end{aligned}
$$

\section{Condenser of the heat pump}

The energy balance of the condenser side of the heat pump in heating mode is specified by eq. A.18 and takes into account the thermal energy content of the inlet and outlet flow of the load side and the power consumption of the main circulation pump $E_{C P}$. Accordingly, the exergy balance (eq. A.19) contains three input terms for the electric energy $E_{C P}$, the exergy content of the inlet flow $X_{H P \text {,load, in }}$ (eq. A.21) and the exergy input from the refrigerant at the condenser $X_{c}$, which can be calculated based on the energy flux between refrigerant and heating fluid $Q_{c}$ (eq. A.20). The exergy of the load side outlet flow $X_{H P, \text { load,out }}$ (eq. A.22) represents the exergy output of the component, while the exergy consumption in the condenser is denoted by $X_{\text {cond. }}$.

$$
\begin{aligned}
& E_{C P}+Q_{c}+c_{w} m_{H P}\left(T_{r e}-T_{0}\right)=c_{w} m_{H P}\left(T_{H P, \text { load }, \text { out }}-T_{0}\right) \\
& E_{C P}+X_{c}+X_{H P, \text { load,in }}-X_{\text {cond }}=X_{H P, \text { load }, \text { out }} \\
& X_{c}=\left(1-\frac{T_{0}}{T_{c}}\right) Q_{c} \\
& X_{H P, \text { load }, \text { in }}=c_{w} m_{H P}\left\{\left(T_{r e}-T_{0}\right)-T_{0} \ln \frac{T_{r e}}{T_{0}}\right\} \\
& X_{H P, \text { load }, \text { out }}=c_{w} m_{H P}\left\{\left(T_{H P}-T_{0}\right)-T_{0} \ln \frac{T_{H P, \text { load,out }}}{T_{0}}\right\}
\end{aligned}
$$

The temperature of the fluid leaving the condenser of the heat pump, $T_{H P, \text { load,out, }}$ is not specified in the system specifications, as it highly depends on the actual values of the system parameters and the heat pump performance during operation. Based on the given parameters and the previous calculations, it 
can be inferred by substituting $Q_{C}$ in eq. 15 with the terms in eq. A.18, and rearranging the obtained equation to obtain $T_{H P, \text { load, out }}$ (eq. A.23):

$$
T_{H P, \text { load }, \text { out }}=\frac{Q_{e}+E_{c o m p}+E_{C P}+c_{w} m_{H P}\left(T_{r e}-T_{0}\right)}{c_{w} m_{H P}}+T_{0}
$$

\section{C: Exergy equations for the system model in cooling mode}

The equations defining the energy and exergy balances and contents of the individual subsystems in cooling mode are set up in the same manner as for heating mode using the general equation for cool exergy (eq. 2). The heat exchanger and HX mixing valve components are not used in cooling mode. The exergy content of the inlet and outlet flows of the individual components, such as $X_{b, i n}$ and $X_{H P \text {,load,out, }}$ can be calculated using the same equations as for heating. For the exergy values of the borehole heat exchanger component the same equations as for heating can be used, with the difference that it comprises cool exergy, i.e. $\left(-Q_{g}\right)$.

In cooling mode the heat pump is operating in reverse mode, as compared to heating mode. The condenser exchanges heat with the ground loop, while the evaporator is connected the cooling circuit, so that the equations have to be reformulated accordingly. Eqs. A.24 and A.25 define the energy and exergy balances of the condenser side of the heat pump in cooling mode with exergy inputs from the geothermal fluid, $X_{b, \text { out }}$, and the ground loop pump, $E_{\text {pump }}$, as well as an output to the BHE, $X_{b, i n}$. The calculation of the output $X_{c}$ is based on the equation for cool exergy (eq. A.26), and the overall energy balance of the ground takes into account $Q_{c}$ (eq. A.27), instead of $Q_{e}$.

$$
\begin{aligned}
& E_{\text {pump }}+c_{b} m_{b}\left(T_{b, \text { out }}-T_{0}\right)=c_{b} m_{b}\left(T_{b, \text { in }}-T_{0}\right)+\left(-Q_{c}\right) \\
& E_{\text {pump }}+X_{b, \text { out }}-X_{\text {cond }}=X_{b, \text { in }}+X_{c} \\
& X_{c}=\left(1-\frac{T_{0}}{T_{c}}\right)\left(-Q_{c}\right) \\
& E_{\text {pump }}+Q_{c}=Q_{g}
\end{aligned}
$$

In the refrigerant cycle $Q_{e}$ now represents and input, and $Q_{c}$ an output (eq. A.28). The same accounts for $X_{e}$ and $X_{c}$ in the exergy balance, respectively (eq. A.29).

$$
\begin{aligned}
& E_{\text {comp }}+Q_{e}=Q_{c} \\
& E_{\text {comp }}+X_{c}-X_{\text {refcycle }}=X_{e}
\end{aligned}
$$

According to the operation in reverse mode, the energy balance of the evaporator accounts for cool exergy in form of $\left(-Q_{e}\right)$ (eq. A.30). In contrast to heating mode, the exergy balance of this component (eq. A.31) takes into account the input by the main circulation pump, $E_{C P}$, and $X_{e}$, which also comprises cool exergy (eq. A.32).

$$
\begin{aligned}
& E_{C p}+\left(-Q_{e}\right)+c_{w} m_{H P}\left(T_{r e}-T_{0}\right)=c_{w} m_{H P}\left(T_{H P, \text { load }, \text { out }}-T_{0}\right) \\
& E_{C P}+X_{e}+X_{H P, \text { load }, \text { in }}-X_{\text {evap }}=X_{H P, \text { load }, \text { out }} \\
& X_{e}=\left(1-\frac{T_{0}}{T_{e}}\right)\left(-Q_{e}\right)
\end{aligned}
$$


For the mixing valve after the heat pump the same equations as for heating can be used. However, in cooling mode the fluid leaving the mixing valve represents the final cooling supply flow into the radiant ceiling (eq. A.33).

$$
X_{\text {sup }}=c_{w} m_{C P}\left\{\left(T_{\text {sup }}-T_{0}\right)-T_{0} \ln \frac{T_{\text {sup }}}{T_{0}}\right\}
$$

In the energy balance for the radiant ceiling, the output energy has to be considered as cool exergy, ($Q_{\text {out }}$ (eq. A.34). While the exergy balance is identical to heating (eq. 28), the exergy delivered to the room $X_{\text {out }}$, is assigned a negative sign, because of the direction of the exergy flow given by $T_{r e}<T_{\text {in }}<$ $T_{0}$ (eq. A.35). The overall energy balance of the cooling loop contains the output term $Q_{e}$ (eq. A.36).

$$
\begin{aligned}
& c_{w} m_{C P}\left(T_{\text {sup }}-T_{\text {ind }}\right)=c_{w} m_{C P}\left(T_{\text {re }}-T_{\text {ind }}\right)+\left(-Q_{\text {out }}\right) \\
& -X_{\text {out }}=\left(1-\frac{T_{0}}{T_{\text {ind }}}\right)\left(-Q_{\text {out }}\right) \\
& E_{C P}+Q_{\text {out }}=Q_{e}
\end{aligned}
$$

\section{References}

[1] Shukuya M. Exergy: theory and applications in the built environment: Springer Science \& Business Media; 2012.

[2] Abedin AH, Rosen MA. Assessment of a closed thermochemical energy storage using energy and exergy methods. Appl Energ. 2012;93:18-23.

[3] Ammar Y, Joyce S, Norman R, Wang Y, Roskilly AP. Low grade thermal energy sources and uses from the process industry in the UK. Appl Energ. 2012;89:3-20.

[4] Oladiran MT, Meyer JP. Energy and exergy analyses of energy consumptions in the industrial sector in South Africa. Appl Energ. 2007;84:1056-67.

[5] Park S, Pandey A, Tyagi V, Tyagi S. Energy and exergy analysis of typical renewable energy systems. Renewable and Sustainable Energy Reviews. 2014;30:105-23.

[6] Hepbasli A. A key review on exergetic analysis and assessment of renewable energy resources for a sustainable future. Renewable and Sustainable Energy Reviews. 2008;12:593-661.

[7] Vats K, Tiwari G. Energy and exergy analysis of a building integrated semitransparent photovoltaic thermal (BISPVT) system. Appl Energ. 2012;96:409-16.

[8] Chow TT, Pei G, Fong K, Lin Z, Chan A, Ji J. Energy and exergy analysis of photovoltaic-thermal collector with and without glass cover. Appl Energ. 2009;86:310-6.

[9] Zhai H, Dai Y, Wu J, Wang R. Energy and exergy analyses on a novel hybrid solar heating, cooling and power generation system for remote areas. Appl Energ. 2009;86:1395-404.

[10] Tempesti D, Manfrida G, Fiaschi D. Thermodynamic analysis of two micro CHP systems operating with geothermal and solar energy. Appl Energ. 2012;97:609-17.

[11] Tchanche B, Lambrinos G, Frangoudakis A, Papadakis G. Exergy analysis of micro-organic Rankine power cycles for a small scale solar driven reverse osmosis desalination system. Appl Energ. 2010;87:1295-306. 
[12] Wang J, Dai Y, Gao L. Exergy analyses and parametric optimizations for different cogeneration power plants in cement industry. Appl Energ. 2009;86:941-8.

[13] Cayer E, Galanis N, Desilets M, Nesreddine H, Roy P. Analysis of a carbon dioxide transcritical power cycle using a low temperature source. Appl Energ. 2009;86:1055-63.

[14] Rosen MA. Assessing energy technologies and environmental impacts with the principles of thermodynamics. Appl Energ. 2002;72:427-41.

[15] Rocco M, Colombo E, Sciubba E. Advances in exergy analysis: a novel assessment of the Extended Exergy Accounting method. Appl Energ. 2014;113:1405-20.

[16] Dincer I, Rosen MA. Exergy as a Driver for Achieving Sustainability. Int J Green Energy. 2004;1:119.

[17] Torío H, Angelotti A, Schmidt D. Exergy analysis of renewable energy-based climatisation systems for buildings: A critical view. Energ Buildings. 2009;41:248-71.

[18] Yildiz A, Güngör A. Energy and exergy analyses of space heating in buildings. Appl Energ. 2009;86:1939-48.

[19] Schmidt D. Low exergy systems for high-performance buildings and communities. Energ Buildings. 2009;41:331-6.

[20] Hepbasli A. Low exergy (LowEx) heating and cooling systems for sustainable buildings and societies. Renewable and Sustainable Energy Reviews. 2012;16:73-104.

[21] Sakulpipatsin P, Itard LCM, van der Kooi HJ, Boelman EC, Luscuere PG. An exergy application for analysis of buildings and HVAC systems. Energ Buildings. 2010;42:90-9.

[22] Fan B, Jin X, Fang X, Du Z. The method of evaluating operation performance of HVAC system based on exergy analysis. Energ Buildings. 2014;77:332-42.

[23] Du Z, Jin X, Fan B. Evaluation of operation and control in HVAC (heating, ventilation and air conditioning) system using exergy analysis method. Energy. 2015;89:372-81.

[24] Yucer CT, Hepbasli A. Thermodynamic analysis of a building using exergy analysis method. Energ Buildings. 2011;43:536-42.

[25] Gonçalves P, Gaspar AR, da Silva MG. Comparative energy and exergy performance of heating options in buildings under different climatic conditions. Energ Buildings. 2013;61:288-97.

[26] Dovjak M, Shukuya M, Olesen BW, Krainer A. Analysis on exergy consumption patterns for space heating in Slovenian buildings. Energ Policy. 2010;38:2998-3007.

[27] Zhou Y, Gong G. Exergy analysis of the building heating and cooling system from the power plant to the building envelop with hourly variable reference state. Energ Buildings. 2013;56:94-9.

[28] Lohani SP. Energy and exergy analysis of fossil plant and heat pump building heating system at two different dead-state temperatures. Energy. 2010;35:3323-31.

[29] Ozturk M. Energy and exergy analysis of a combined ground source heat pump system. Appl Therm Eng. 2014;73:362-70.

[30] Ozgener O, Hepbasli A. A review on the energy and exergy analysis of solar assisted heat pump systems. Renewable and Sustainable Energy Reviews. 2007;11:482-96.

[31] Tolga Balta M, Kalinci Y, Hepbasli A. Evaluating a low exergy heating system from the power plant through the heat pump to the building envelope. Energ Buildings. 2008;40:1799-804. 
[32] Balta MT, Dincer I, Hepbasli A. Performance and sustainability assessment of energy options for building HVAC applications. Energ Buildings. 2010;42:1320-8.

[33] Lohani SP, Schmidt D. Comparison of energy and exergy analysis of fossil plant, ground and air source heat pump building heating system. Renew Energy. 2010;35:1275-82.

[34] Kazanci OB, Shukuya M, Olesen BW. Exergy performance of different space heating systems: A theoretical study. Build Environ. 2016;99:119-29.

[35] Akbulut U, Utlu Z, Kincay O. Exergy, exergoenvironmental and exergoeconomic evaluation of a heat pump-integrated wall heating system. Energy. 2016;107:502-22.

[36] Kilkis B. Enhancement of heat pump performance using radiant floor heating systems. ASME, NEW YORK, NY(USA). 1992;28:119-27.

[37] Kilkis B. Role of Radiant Panel Heating and Cooling in Net Zero Energy Buildings. ASHRAE Transactions. 2011;117.

[38] Li R, Ooka R, Shukuya M. Theoretical analysis on ground source heat pump and air source heat pump systems by the concepts of cool and warm exergy. Energ Buildings. 2014;75:447-55.

[39] Kazanci OB, Shukuya M, Olesen BW. Theoretical analysis of the performance of different cooling strategies with the concept of cool exergy. Build Environ. 2016;100:102-13.

[40] Baccoli R, Mastino C, Rodriguez G. Energy and exergy analysis of a geothermal heat pump air conditioning system. Appl Therm Eng. 2015;86:333-47.

[41] Bi Y, Wang X, Liu Y, Zhang H, Chen L. Comprehensive exergy analysis of a ground-source heat pump system for both building heating and cooling modes. Appl Energ. 2009;86:2560-5.

[42] Soni SK, Pandey M, Bartaria VN. Hybrid ground coupled heat exchanger systems for space heating/cooling applications: A review. Renewable and Sustainable Energy Reviews. 2016;60:724-38.

[43] Atam E, Helsen L. Ground-coupled heat pumps: Part 2-Literature review and research challenges in optimal design. Renewable and Sustainable Energy Reviews. 2016;54:1668-84.

[44] Lubis LI, Kanoglu M, Dincer I, Rosen MA. Thermodynamic analysis of a hybrid geothermal heat pump system. Geothermics. 2011;40:233-8.

[45] Alavy M, Nguyen HV, Leong WH, Dworkin SB. A methodology and computerized approach for optimizing hybrid ground source heat pump system design. Renew Energy. 2013;57:404-12.

[46] Lucia U, Simonetti M, Chiesa G, Grisolia G. Ground-source pump system for heating and cooling: Review and thermodynamic approach. Renewable and Sustainable Energy Reviews. 2017;70:867-74.

[47] Sun X, Wu J, Wang R. Exergy analysis and comparison of multi-functional heat pump and conventional heat pump systems. Energ Convers Manage. 2013;73:51-6.

[48] Shukuya M. Energy, entropy, exergy and space heating systems. Proceedings of the 3rd International Conference "Healthy Building '941994. p. 369-74.

[49] Menberg K, Bayer P, Zosseder K, Rumohr S, Blum P. Subsurface urban heat islands in German cities. Sci Tot Environ. 2013;442:123-33.

[50] Hepbasli A, Akdemir O. Energy and exergy analysis of a ground source (geothermal) heat pump system. Energ Convers Manage. 2004;45:737-53.

[51] Shah R, Focke W. Plate heat exchangers and their design theory. Heat Transfer Equipment Design. $1988 ; 227$. 
[52] UK Government. Department for Business, Energy \& Industrial Strategy, Digest of UK Energy Statistics, 2016. https://www.gov.uk/government/collections/digest-of-uk-energy-statistics-dukes

[53] Bilgen E, Takahashi H. Exergy analysis and experimental study of heat pump systems. Exergy, An International Journal. 2002;2:259-65.

[54] Hepbasli A, Akdemir O, Hancioglu E. Experimental study of a closed loop vertical ground source heat pump system. Energ Convers Manage. 2003;44:527-48. 